\title{
MORTALITY AND MACROECONOMIC FLUCTUATIONS IN CONTEMPORARY SWEDEN 1
}

\author{
José A. Tapia Granados ${ }^{2}$ and Edward L. Ionides ${ }^{3}$
}

\begin{abstract}
Recent research has provided strong evidence that, in the United States in particular and in high- or middle-income economies in general, mortality tends to evolve better in recessions than in expansions. It has been suggested that Sweden may be an exception to this pattern. The present investigation shows, however, that in the period 1968-2003 mortality oscillated procyclically in Sweden, deviating from its trend upward during expansions and downward during recessions. This pattern is evidenced by the oscillations of life expectancy, total mortality, and age- and sex-specific mortality rates at the national level, and also by regional mortality rates for the major demographic groups during recent decades. Results are robust for different economic indicators, methods of detrending, and models. In lag regression models macroeconomic effects on annual mortality tend to appear lagged one year. As in other countries, traffic mortality rises in expansions and declines in recessions, and the same is found for total cardiovascular mortality. However, macroeconomic effects on ischemic heart disease mortality appearing at lag two are hard to interpret. Reasons for the procyclical oscillations of mortality, for inconsistent results found in previous studies, as well as for the differences observed between Sweden and the United States are discussed.
\end{abstract}

\section{Introduction}

In a number of countries and periods it has been found that over and above long-term declining trends, mortality rates tend to rise in expansions and decline in recessions. The main finding of the present investigation is that the same happened in Sweden in the last three decades of the $20^{\text {th }}$ century. Since mortality oscillates procyclically, life expectancy at birth $\left(e_{0}\right)$ oscillates countercyclically and the annual gain in $e_{\mathrm{o}}$ is greater in years of economic downturn than in years of economic expansion. This procyclical oscillation of mortality is shown in the present study using various statistical models, for a range of different mortality

\footnotetext{
${ }^{1}$ This is an expanded version including a number of references, figures and appendices that were supressed in the published version of the paper.

${ }^{2}$ Social Environment \& Health (SEH/SRC) Program, Institute for Social Research, University of Michigan, Ann Arbor. E-mail: jatapia@umich.edu.

${ }^{3}$ Department of Statistics, University of Michigan, Ann Arbor.
} 
rates and business-cycle indicators. These results adds to an emerging consensus that economic expansions rather than recessions have harmful effects for health.

The next two sections review previous work on mortality and the business cycle, and potential pathways linking the economy with mortality. Sections 4 and 5 show the data and methods we have used for the investigation, and the results of our analyses. The last two sections include a discussion of the results of other investigations, and a general discussion of our findings in the context of previous work. In two appendices we have discussed statistical issues that are probably beyond the interest of the average reader of this paper.

\section{Previous Research on Mortality and the Business Cycle}

The relation between mortality and the business cycle was already investigated in the $1920 \mathrm{~s}$ by Ogburn and Thomas, who were surprised by finding a procyclical fluctuation of mortality in the United States and Britain during the business cycles preceding World War I (Ogburn 1964; Ogburn and Thomas 1922; Thomas 1927). These early studies were largely forgotten for most of the $20^{\text {th }}$ century, probably because the idea that mortality evolves better during recessions than during expansions was too counterintuitive to be easily accepted.

The notion that economic hardship must be bad for health, and therefore associated with higher mortality, is deeply ingrained in social science. Many investigations in the fields of public health, demography, and economics have shown that low income is systematically associated with higher death rates (Isaacs and Schroeder 2005). Increasing mortality resulting from a worsening standard of living is the basis of Malthus's "positive check" to population growth, which is a frequent working hypothesis in demography and economic history (Bengtsson and Saito 2000; Bengtsson et al. 2004). Historical studies of preindustrial societies have indeed shown that mortality upswings are associated, for instance, with bad harvests, increases in grain prices, or cold winters (Lee 1981; Schofield 1985; Thomas 1941; LiviBacci 1991). However, this link between mortality and food price inflation or bad harvests is considerably weakened with advances in economic development and industrialization (Galloway 1988). In Sweden, for example, the strong mortality responses to bad harvests ob- 
served in the 18th century and first half of the $19^{\text {th }}$ century (Fridlizius 1979) disappeared during the last decades of the $19^{\text {th }}$ century (Thomas 1941; Tapia Granados and Ionides 2008).

In the 1970s and 1980s, Brenner repeatedly reported harmful effects of recessions on mortality, other health indicators, and social conditions (Brenner 1971, 1979, 1982, 1987). Brenner utilized relatively unconventional econometric techniques such as Fourier analysis, distributed lag regressions, and ARIMA models. These studies, mostly published in health journals, raised protracted controversy. While the results of a few investigations apparently supported Brenner's argument to some extent (Bunn 1979, 1980; Junankar 1991; McAvinchey 1984), other researchers criticized Brenner's studies for deficient presentation of data and methods, use of lags arbitrarily chosen, lack of statistical power with the number of observations being often close to that of covariates, improper methods of detrending, and inclusion of multiple covariates implying strong collinearity (Eyer 1976a, 1976b, 1977a; Kasl 1979; Gravelle Hutchinson, and Stern 1981; Forbes and McGregor 1984; Lew 1979; Winter 1983; Søgaard 1992; Wagstaff 1985). Meanwhile, with straightforward statistical methods Eyer (1977b), Higgs (1979), and Graham et al. (1992) again found a procyclical fluctuation of mortality in the United States.

In recent years a number of publications have reexamined whether macroeconomic fluctuations are related to short-term oscillations in mortality. In a ground-breaking study, Ruhm (2000) applied panel regressions to data from the 50 states of the United States during the years 1972-1991, showing that beyond long-term trends, periods of expanding economic activity-gauged by low state unemployment levels-were associated with increased mortality, that is to say, that mortality oscillates procyclically. Other work using panel regressions has shown that the 1981-1982 recession induced substantial reductions of atmospheric pollution associated with significant drops in infant mortality (Chay and Greenstone, 2003); that babies born during recessions in the United States have a reduced incidence of low birth weight and lower infant mortality (Dehejia and Lleras-Muney 2004); and that death rates oscillate procyclically in Japan (Tapia Granados 2008), the 16 German states 
(Neumayer 2004), the 50 Spanish provinces (Tapia Granados 2005a), the 96 French départements (Buchmueller at al. 2007), and the 23 OECD countries (Johansson 2004; Gerdtham and Ruhm 2006). The procyclical oscillations of mortality in the United States have also been confirmed using time-series analyses (Laporte 2004; Tapia Granados 2005b) and individual-level data from the National Longitudinal Mortality Study (Edwards 2008). The evolution of mortality rates and life expectancy in the United States during the 1920 s and 1930s shows that mortality-based health indicators evolved better during the Great Depression of 1929-1933 than during the economic expansions of the "roaring" twenties and midthirties (Tapia Granados and Diez Roux 2009). In medium-income market economies mortality responses to macroeconomic downturns have been found to be erratic (Tapinos et al. 1997) or even clearly procyclical (Abdala et al. 2000; Khang et al. 2005; Tapia Granados 2006; González and Quast 2010).

Sweden has been the focus of four recent studies by Gerdtham and Johannesson (2005), Tapia Granados and Ionides (2008), and Svensson (2007, 2010), which provide conflicting evidence on the relation between macroeconomic fluctuations and mortality in that country. The existence and nature of this relation in Sweden seems important because (a) Sweden is a world leader in health indicators and levels of income per capita; (b) the Swedish welfare state is one of the most developed in the world, with universal health care and generous income support for unemployed people provided by the State; and (c) the Swedish economy went through major fluctuations in the last decades of the $20^{\text {th }}$ century (see for instance the wide fluctuations of unemployment, figure 1).

The study by Gerdtham and Johannesson (2005) used a sample of 47,484 adults interviewed in Sweden in 1980-1996 and followed through the end of 1996, for a total of 6,571 deaths. Using a probit model Gerdtham and Johannesson modeled the probability of death as a function of age, the state of the economy (proxied by a business-cycle indicator), and a linear trend. They found mortality increasing during economic downturns and decreasing in upturns-i.e., a countercyclical fluctuation of mortality-though only for male mortality, and only for four business-cycle indicators (notification rate, capacity utilization, confidence in- 
dicator, and GDP growth) out of six that they considered (the aforementioned, plus unemployment and GDP deviation from trend).

Tapia Granados and Ionides (2008) investigated the relation between economic growth and health progress in Sweden during the $19^{\text {th }}$ and $20^{\text {th }}$ centuries. They found that annual economic growth was positively associated with mortality decline throughout the 19th century, though the relation became weaker as time passed and was reversed in the second half of the 2oth century, during which higher economic growth was associated with lower drops in mortality. While the economy-related effect on health occurs mostly at lag zero in the 19th century, the effect is lagged up to two years in the $20^{\text {th }}$ century. These results implying a procyclical fluctuation of mortality rates after 1950 were found to be robust across a variety of mortality rates (sex-, age-, and age- and-sex-specific), statistical procedures (including linear regression, spectral analysis, and lag regression models), and economic indicators (GDP per capita growth, unemployment, and some measures of inflation). This study did not investigate effects for periods shorter than a half century or for cause-specific mortality, but its results indicate that macroeconomic changes (indexed by annual GDP growth or the annual change in unemployment) have a lagged effect on the annual change in mortality, mostly at lag one.

In two different studies Svensson $(2007,2010)$ has employed panel regressions to analyze annual rates of mortality and unemployment in the 21 Swedish regions during 1976-2005. He could not detect any relation between mortality (neither total nor sex-specific) and unemployment that was robust to different specifications including year-fixed effects, regionspecific linear trends or other methods to avoid potential bias. Therefore, he was unable to replicate the countercyclical oscillation of male mortality reported by Gerdtham and Johannesson (though Svensson downplays this inconsistency between his results and those of Gerdtham and Johannesson). The only robust procyclical oscillation found by Svensson is for mortality due to work-related injuries, which increase in expansions. Other causespecific mortality rates were found to be procyclical or countercyclical depending on the specification. Svensson found ischemic heart disease mortality to be consistently counter- 
cyclical, though only among those aged 20 to 49 and at the 0.1 level of statistical significance.

\section{Pathways Linking the Economy and Mortality}

Potential pathways leading to a procyclical fluctuation of mortality (figure 2) have been extensively discussed elsewhere (Ruhm 2000, 2004, 2005a; Tapia Granados 2005a; Eyer 1984; Neumayer 2004). They will only be briefly summarized here.

Mortality caused by diseases of the circulatory system, that is, cardiovascular disease (CVD) mortality, is usually the main component of total mortality in most countries. It has been hypothesized that procyclical oscillations of CVD mortality may result from a variety of CVD risk factors that increase during expansions (Eyer 1977b; Ruhm 2000, 2005b; Tapia Granados 2005b, 2008). These would include stress in the working environment-because of overtime and increased rhythm of work (Sokejima and Kagamimori 1998)—, reduced sleep time (Biddle and Hamermesh 1990), atmospheric pollution, smoking, and consumption of saturated fat and alcohol (Ruhm 2005c). Many of these factors might increase the risk of death of persons who had a previously developed chronic disease, such as cancer, diabetes, a respiratory illness, or a chronic infection. The increase in traffic deaths during economic booms and the decrease in recessions is a robust finding across countries (Eyer 1977b; Ruhm 2000; Neumayer 2004; Tapia Granados 2005a, 2005b; Khang et al. 2005). The strong procyclical fluctuation of traffic-related injuries and deaths is intuitively explained by the fact that commuting, commercial, and recreational traffic rapidly expand in economic upswings (Baker et al. 1984; Ruhm 2000), and the effect is probably aggravated by the procyclical change in alcohol consumption and by sleep deprivation in expansionary periods in which overwork is frequent (Biddle and Hamermesh 1990; Liu et al. 2002).

Increased infant mortality in expansions has been related to economic activity through atmospheric pollution (Chay and Greenstone 2003) and healthier behaviors of pregnant women during recessions (Dehejia and Lleras-Muney 2004). In addition, in high-income economies injury deaths are a quite large proportion of the small annual number of infant 
and children deaths. Thus, in this context economic expansions could be associated to an above-trend level of infant and child mortality through car crashes as well as domestic or school injuries related to overworked parents or caretakers.

\section{Data and Methods}

In the present investigation crude, and sex- and age-specific mortality rates were computed from deaths and population in five-year age strata taken from Statistics Sweden (2005). Data on annual unemployment rates, real GDP, industrial production, and the confidence indicator for the manufacturing industry were obtained from the same source. Infant mortality and age-standardized mortality rates were taken from the WHO-HFA (2005) database. ${ }^{4}$ Four indices of Swedish manufacturing activity (average hours, aggregate hours, manufacturing output and manufacturing employment) were obtained from the U.S. Bureau of Labor Statistics (2005). Data on life expectancy at birth are from the Human Mortality Database (2005).

Our main analysis employs data from Swedish annual statistics (figure 1), from 1968 to the early 2000 (usually until 2003, with $n$ equal to 35 or 36 in most series). This time frame was chosen for two reasons: first, because it is possible that the relation between macroeconomic changes and health progress changed over time, and the focus of this investigation is contemporary Sweden; second, because a number of cause-specific and age-adjusted mortality rates for Sweden are available from the WHO Health-For-All database beginning in 1968 or 1970. The reference chronology of the Organisation for Economic Cooperation and Development (OECD 2006) indicates that there were 10 business cycle troughs in Sweden (figure 1) between 1968 and 2003.

\footnotetext{
4 In the HFA database age-standardized rates are computed with the direct method, applying agespecific rates for 5-year age-strata (o-4, 5-9, etc.) to a standard European population. For instance, the standardized rate of cancer mortality at ages o-64 represents what the age-specific rate at ages o64 would have been if the Swedish population aged o-64 had the same age distribution as the standard European population.
} 
Population health is indexed by life expectancy at birth ( $e_{0}$, "life expectancy" for brevity) and a variety of age-, sex-, and cause-specific mortality rates. Since life expectancy is the best mortality-based summary index of population health, unaffected by the age structure of the population and allowing intertemporal and cross-sectional comparisons (Shryrock et al. 1973), we based many of our analysis in $\Delta e_{0}$, the annual gain in life expectancy, as a major indicator of health progress.

Analyses in this paper are either $(a)$ simple correlation models between health and economic indicators, or $(b)$ lag regressions in which a health indicator is regressed on contemporaneous and lagged values of an economic indicator. Strong collinearity between business cycle indicators precludes using combinations of these indicators in the same multivariate regression model. Since both the indicators of population health and the economic indicators used in the study have obvious trends (figure 1), all variables were detrended before analysis to produce trend-stationary series. Several procedures to detrend variables were used; only results obtained either with "HP detrended" series (i.e., series obtained by subtracting the trend computed with the Hodrick-Prescott filter5 from the actual value of the variable) or with variables transformed into first differences $\left(\Delta x_{t}=x_{t}-x_{t-1}\right)$ or rate of change $\left(\Delta x_{t} / x_{t-1}\right)$ are presented. Other detrending procedures ${ }^{6}$ were employed in sensitivity analyses and yielded similar results.

Macroeconomic fluctuations are not easy to identify and delimit, and not all the different business cycle indicators gauge them in the same way (Mitchell 1951; Backus et al. 1992; Baxter and King 1999). In the present study, eight economic indicators were used: GDP, the unemployment rate, the index of industrial production, the confidence indicator and four indices of activity in manufacturing: average working hours, aggregate hours, output and employment. All of them show significantly correlated fluctuations except the confidence indicator which fluctuates without a definite relation to the others. For the sake of brevity

\footnotetext{
5 We used a smoothing parameter $\gamma=100$ (figure 1), as advised for annual data (Backus and Kehoe 1992). Appendix A defends this option.

${ }^{6}$ We used the HP filter applied with $\gamma=10$, and the band-pass filter $\operatorname{BP}(2,8)$, recommended by Baxter and King (1999).
} 
results for only three business cycle indicators-real GDP, the unemployment rate, and the index of average working hours in manufacturing-will be presented here. At lag zero, detrended unemployment and GDP have a strong negative correlation in this Swedish sample ( -0.75 when both series are in rate of change, -0.85 when both are detrended with the Hodrick-Prescott filter, for both correlations $P<0.001)$. The index of average hours worked in manufacturing correlates positively and significantly with unemployment $(0.40, P=0.01$, both series HP-detrended) at lag zero. Therefore both unemployment and average hours are countercyclical, while GDP is procyclical.7

Cross-correlations and distributed lag regression models were used to ascertain the concomitant variation between "health" and "the economy" or the coincident or lagged effect of the latter on the former. Cross-correlations between detrended series have been used to analyze the historical properties of business cycle indicators (Galbraith and Thomas 1941; Backus and Kehoe 1992), biological and medical data (Diggle 1990), and time-series experiments (Glass et al. 1975). Distributed lag regressions are a common tool in econometrics. For the sake of consistency, the two variables correlated or used as outcome and explanatory variables in a regression were always detrended by the same method. ${ }^{8}$ In lag regressions we used the Akaike information criterions (AIC) as an objective approach to choose among the multiple models that we investigated. Although AIC has its strengths and flaws relative to other model selection criteria, such as BIC and adjusted $\mathrm{R}^{2}$ (Claeskens 2008), to minimize AIC is a common and generally accepted procedure to choose "the best" model among models with different lags.

\footnotetext{
7 Business cycle data for the United States and other industrialized countries show average working hours in manufacturing as a procyclical indicator; in Sweden, however, its strong positive correlation with unemployment shows that it is clearly a countercyclical one. We comment on the potential causes of this difference in the general discussion section.

${ }^{8}$ In fact, there is an exception to this rule, because in some models first differences in $e_{0}$ or mortality are regressed on the rate of growth of GDP. GDP growth is a major dynamic index of business conditions and, moreover, because of the exponential growth of real GDP, first differences tend to present exploding heteroskedasticity when the series exceeds a few observations.
} 
In supplementary analyses, utilizing panel regression models we also analyzed Swedish mortality rates and unemployment rates for the 21 Swedish regions in the years 19762005. These data were kindly shared with us by Mikael Svensson, and correspond to the data used in his two papers (Svensson 2007 and 2010). We obtained the population data for the regional analysis from Statistics Sweden.

\section{Results}

\subsection{Correlation Models}

For the whole population and for large age groups, and with series HP-detrended, mortality has positive correlations with GDP and negative correlations with unemployment and average hours (table 1). Life expectancy at birth, $e_{0}$, follows the same pattern with reversed signs, as is to be expected if mortality is procyclical. ${ }^{9}$ Out of 54 correlations of detrended economic indicators with detrended health indicators (table 1), only four correlations have a sign that is inconsistent with a procyclical oscillation of mortality.

When age- and sex-specific mortality rates are correlated with the economic indicators, with variables either HP-detrended (table 2, bottom panel) or in rate of change (table 2, top panel), the correlations of the HP-detrended variables with the economic indicators are much stronger. However, the direction of the correlations is consistently similar in analyses involving rate of change or HP-detrended series, suggesting that the HP-filtering is not introducing spurious results in terms of the sign or direction of correlations with mortality rates. Leaving aside the correlations that are statistically indistinguishable from zero, almost without exception the correlations of age- and sex-specific mortality rates with unemployment and average hours are negative, while the correlations of mortality rates with GDP are positive (table 2). As observed for larger demographic groups (table 1), the pattern of signs in the correlations of age-and sex-specific mortality rates (table 2) indicate a procyclical os-

\footnotetext{
9 The other three manufacturing indicators (aggregate hours, output, and employment) and the index of industrial production correlate similarly with mortality and $e_{0}$. The confidence indicator has erratic correlations with both the other business cycle indicators and with the health indicators.
} 
cillation of mortality for most age groups. The high correlations between detrended business cycle indicators and detrended mortality for ages 10-19 and 20-44 are apparent in the fluctuations of these death rates following the swings of the economy (figure 3).

During the period of the study, the unemployment rate oscillated very moderately in Sweden before 1990, never exceeding $3 \%$, but in the early 1990 os unemployment rose to around $10 \%$, remaining there for most of the decade (figure 1). Correlations between mortality rates and economic indicators computed in split samples corresponding to the years in which unemployment was low (1968-1989) or high (1989-2003) reveal that the results are quite robust (table 3). In split samples the correlations of life expectancy and mortality rates with the countercyclical unemployment and average hours and with the procyclical GDP all show an increase in death rates during expansions. However, with smaller samples fewer results are significant and in some cases even coefficient signs are unstable.

The zero-lag correlations of detrended series of cause-specific mortality with detrended economic indicators (table 4) indicate a strong procyclical oscillation of traffic mortality, which shows strong positive correlations with GDP and strong negative correlations with unemployment and average hours. CVD mortality does not reveal any clear relation with business fluctuations at lag zero. One of its components, ischemic heart disease mortality or "heart attacks"-causing about one half of total CVD deaths - correlates negatively with GDP (- 0.29) and positively (0.28) with unemployment, at marginal or not significant levels when considering all ages. However, at ages over 64 the correlations have the same sign, but they are much stronger, all of which suggests that ischemic heart disease at advanced ages fluctuates countercyclically in Sweden when considering lag zero effects only. Cerebrovascular disease (stroke) mortality comprises about one fifth of all CVD deaths and does not reveal any definite relation with business cycle indicators at lag zero. ${ }^{10}$

\footnotetext{
${ }^{10}$ Table 4 and other tables omit the results for cancer, respiratory disease, infectious disease, flu, suicide and homicide, causes for which we could not find a conclusive relation with macro-economic fluctuations.
} 
5.2 Lag Regression Models

We explored the joint effect on health of coincidental and lagged changes in the economy with models of the type $H_{t}=\alpha+\sum_{i=0}^{p} \beta_{i} x_{t-i}$ including $p$ lags, in which $H_{t}$ is a health indicator at year $t$ and $x_{t-i}$ is an economic indicator at year $t-i$. In these models, health is indexed by $e_{\mathrm{o}}$ or an age-specific mortality rate, and the explanatory variable is either unemployment, GDP, or average hours in manufacturing. Variables are detrended by conversion either in first differences or in rate of change. In general, in models using different methods of detrending, the estimated effects were consistent in sign. For a variety of health indicators we explored models in which the economy is indexed by an indicator (GDP, unemployment, or average hours) including several lags (table 5). For life expectancy, crude mortality, or agespecific mortality for large age-groups (table 5), AIC values indicate that models including a coincidental effect at lag zero and a lagged effect at lag one are to be preferred when the economic indicator used as regressor is GDP growth or the change in unemployment. However, when the regressor is average hours, the models including lag zero only are those that minimize AIC. All these distributed lag models in which either GDP or unemployment is the economic covariate (table 5, panels A and B) show a significant effect on health at lag one, but when the economic indicator is average hours the effect is at lag zero. GDP growth has a significant negative effect on life expectancy, while unemployment and average hours have significant positive effects. Similar patterns are observed for crude mortality or mortality for specific ages. Interpreting the sign of the net effect, most of these models suggest procyclical mortality, but considering the size of the net effect (adding up effects at lags zero and one), only the model for mortality at ages 45-64 regressed on GDP growth (table 5, panel A) reaches marginal significance (the net effect is $0.003+0.022=0.025$ has an standard error $\mathrm{SE}=0.013 ; P=0.09$ ). Models with average hours as economic indicator (table 5, panel $\mathrm{C}$ ) only require one lag and they suggest procyclical mortality when the economic indicator is either life expectancy, crude mortality, or mortality at ages 45-64. 
In these regression models (table 5), the Durbin-Watson $d$ is usually either close to 2.0 or above 2.0. Since $d=2[1-r]$, where $r$ is the estimated autocorrelation, $d \geq 2$ implies evidence against positive autocorrelation of the residuals which would result in underestimates of standard errors and spurious significance. ${ }^{11}$

We also examined some models in which an age-standardized mortality rate is regressed on coincidental or lagged GDP growth (table 6). For all-cause mortality, sex-specific ageadjusted mortality for both males and females and sex-specific age-adjusted mortality in ages 25-64 (table 6, panel A), the specification minimizing AIC is the one including effects at lags zero and one. With only a few exceptions in which lag-two effects are also needed, this is also true for CVD mortality in different demographic groups (table 6, panel B). However, for traffic mortality (table 6, panel B, bottom) the minimization of AIC occurs in specifications including just lag-zero effects.

For total mortality, male mortality and female mortality and for male mortality at ages 25-64 predominantly positive and statistically significant effects of GDP growth on mortality at lag one indicate a procyclical oscillation of mortality rates. For CVD mortality at all ages and ages below 65, positive (and significant) effects of GDP growth at lag one also indicate a procyclical oscillation of this type of mortality. However, for CVD mortality at ages 65 and over what predominates is negative effects of GDP growth (at lags zero and two).

In regressions modeling coincidental and lagged effects of GDP growth on ischemic heart disease mortality (table 6, panel B), almost without exception there are negative effects at lag zero and positive effects at lag one, and the positive effects at lag one are often statistically significant and predominant. However, for ischemic heart disease mortality in males the

\footnotetext{
${ }^{11}$ In only a few cases $d$ is large enough to suggest negative autocorrelation (see footnote in table 5). Adjusting for autocorrelation of the residuals did, as expected, produce similar parameter estimates with some additional statistical significance To avoid the need to justify selection of a specific autocorrelated model, we simply present the conservative unadjusted values. For further discussion of these issues, see appendix B.
} 
model minimizing AIC also includes effects at lag two and the net effect of GDP growth on this type of mortality in males is negative, i.e. ischemic heart disease mortality decreases with greater GDP growth. Overall, this indicates a countercyclical oscillation of ischemic heart disease mortality. However, the effects at lag two are difficult to interpret. Business cycles over recent decades in Sweden last approximately 4 years (according to the OECD chronology, the mean $\pm \mathrm{SD}$ of the trough-to-trough distance is $3.8 \pm 1.4$ years). This implies that an effect of high GDP growth lagged two years will likely occur actually when GDP growth is already low in the next phase of the cycle. For ischemic heart disease at ages 85 and over, there are negative effects at lags zero and two and a significant positive effect at lag one, so that the net effect of GDP growth is negative, the positive effect for lag one is statistically significant but the net effect is not .

Overall, considering lag regression models (tables 5 and 6) and correlations (tables 1 to 4) for the period 1968-2003, the results are consistent for major health indicators. Results for life expectancy, total mortality, and crude or age-adjusted total mortality in large age groups indicate a procyclical fluctuation of death rates for the whole population and for both males and females. Less consistent are the correlations and regression results for age-specific mortality rates. The link between economic expansions (recessions) and increases (falls) in mortality rates seems to be stronger in adolescents, young adults and adults of middle age. Infant mortality also fluctuates procyclically. Results for ages $65-84$ or over 65 are equivocal, and for mortality at ages 85 and over we could not find any statistically significant evidence of a link with business cycle fluctuations.

\subsection{Size of the Effect}

The net effects of GDP growth at lags zero $)$ and lag one $(-0.97+3.35=2.32)$ on total ageadjusted mortality measured per 100,000 population (table 6, panel A) imply that each extra percentage point in GDP growth will increase mortality in about 2.32 deaths per 100,000. In recent years the age-standardized death rate is 600 per 100,000. Since the Swedish population is about 9 million, each percentage point increase in GDP growth would cause 
$\left[2.32 / 10^{5}\right] \cdot 9 \cdot 10^{6}=209$ extra deaths, or an increase of a slightly less than half a percent $(2.32 / 600=0.4 \%)$ in age-adjusted mortality. During the period of study GDP growth oscillated between $-2 \%$ in major downturns and $6 \%$ in major expansions. Therefore, a typical expansion in which GDP growth increases three or four percentage points would increase age-adjusted mortality between one and two percentage points, with an additional death toll of 600 to 800 fatalities.

Modeling the relation between macroeconomic change and health using the annual variations in unemployment $\left(\Delta U_{t}\right)$ and life expectancy $\left(\Delta \mathrm{e}_{o, t}\right)$ the estimated equation (error term omitted) is

$$
\Delta \mathrm{e}_{\mathrm{o}, \mathrm{t}}=0.164-0.026 \cdot \Delta U_{t}+0.076 \cdot \Delta U_{t-1}
$$

(this is model [6] in table 5). It implies a gain of 0.164 years in life expectancy from time $t-1$ to time $t$ after no change in unemployment from time $t-2$ to time $t-1$ and from time $t-1$ to time $t$ (that it, $\Delta U_{t}=\Delta U_{t-1}=0$ ). On the other hand, the gain in life expectancy will be zero $\left(\Delta e_{0, t}=0\right)$ with two successive equal drops in annual unemployment of 3.3 percentage points-which in macroeconomic terms means a brisk economic expansion-while greater annual drops in unemployment will reduce life expectancy. A recession in which unemployment grows 2 percentage points for two consecutive years $\left(\Delta U_{t}=\Delta U_{t-1}=2\right)$ will be associated with an annual increase of 0.264 years in life expectancy, a gain 2.3 times greater than the o.114 years gained in an expansion during which the unemployment rate consecutively drops one percentage point per year $\left(\Delta U_{t}=\Delta U_{t-1}=-1\right)$. For reference, it is important to note that during the period included in this investigation life expectancy at birth increased about 5 years during three decades, for an annual gain of 0.18 years, while the unemployment rate never increased more than 3.8 percentage point or dropped more than 1.3 points per year.

\section{Results of Other Investigations on Sweden}

The sample in Gerdtham and Johannesson's study is very large, including over 500,000 person-year observations (Gerdtham and Johannesson 2005, p. 205), However, their analysis only includes 6,571 deaths occurring over 16 years, while our analyses include all deaths that 
occurred in Sweden for each year of the study period, i.e., over 90,000 deaths per year for a total of over 3 million deaths during 1968-2002. National death rates give greater statistical power than a sample of 6,571 deaths to investigate various model specifications and, particularly, to check model consistency across population subgroups. The sample size limitations in the analyses reported by Gerdtham and Johannesson are illustrated for example by the fact that they had only 43 traffic-related deaths (p. 214), which implied that the businesscycle impact on this cause of death could not be analyzed. Moreover, though Gerdtham and Johannesson present some supplementary analyses using education and income as individual-level covariates, the only individual covariate used in their primary analysis is the age at death. We also control for age in our analyses by using the aggregate measures of life expectancy and age-specific mortality rates.

According to Gerdtham and Johannesson (p. 210), when quadratic and cubic trends were included in their models, some statistically significant results were weakened. Since linear trends may be insufficient to account for the long-term curvilinear trends in indicators of the Swedish economy in recent decades (figure 1), the imperfect control for these trends may have produced biased results. For instance, the enormous size of the effect of macroeconomic change on cancer mortality reported by Gerdtham and Johannesson may imply model misspecification. Similarly, their finding that results vary from procyclical to countercyclical fluctuation of mortality depending on the economic indicator used suggests instability in the results. There are also limitations to the indicators they used. For example, opinion-based variables such as the confidence indicator or the notification rate may be very imperfect indicators of the fluctuations of the real economy. Indeed, we have verified that the confidence indicator, one of the indicators rendering countercyclical results for mortality in Gerdtham and Johannesson's investigation, reveals a very erratic relation with GDP, unemployment, and all the other business indicators based on manufacturing, and is therefore likely to be a very unreliable index (neither procyclical nor countercyclical) of the changes in the real economy. 
Another limitation of Gerdtham and Johannesson's investigation is the short period of data collection, which allows for few recurrent changes in the state of the economy. In their paper they state (p. 209) that the relation between unemployment and probability of death is negative for unemployment (so that mortality is procyclical) over the whole study period, 1981-1996, but turns positive (counter-cyclical) for male, and zero for females, in the subperiod 1981-1991. Gerdtham and Johannesson consider the procyclical mortality result obtained for the years 1981-1996 to be biased by the high unemployment in the 1990s. However, if there is a real relation (whether procyclical or countercyclical) between the fluctuations of the economy and the mortality risk, the relation will tend to appear most clearly in samples covering longer periods and will tend to became unstable or to disappear as the analyzed period gets shorter and closer to the average duration of business cycles. This instability is shown, for instance, by our split-sample correlations of HP-detrended unemployment and mortality at ages $45^{-64}$ (table 3 in the present paper). The correlation between these variables is positive (i.e., a countercyclical fluctuation of mortality) in the years 1981-1992 (the sample often used by Gerdtham and Johannesson), though it is negative (suggesting procyclical mortality) in other split samples (table 3, panel B), and over the whole period 1969-2003 (table 1). Business cycles may vary in length "from more than one year to ten or twelve years"-a classical definition by Mitchell $(1951$, p. 6) that fits very well with the data analyzed here, with macroeconomic fluctuations on average 4 years long. Therefore, ten years may be too short a period to study any business-cycle-related issue. Indeed, the period 1981-1991 that Gerdtham and Johanesson often use to present results is one in which unemployment changed very little and GDP growth varied within very narrow limits (figure 1). Observing only part of the full range of variation of a covariate is one of the potential causes of biased results in any statistical model.

Most of the results supporting a countercyclical oscillation of mortality (only for males) in Gerdtham and Johannesson's investigation come from models in which the only considered effect of the economy on mortality is a coincidental one. As reported by the authors, adding lagged variables with lags up to four years produced procyclical mortality effects at $t-1$ for 
both unemployment and GDP deviation from trend. However, since the coefficients for the lagged economic indicator in these specifications are not reported by Gerdtham and Johannesson, it is not possible to evaluate the net effect.

It is also important to note that a positive impact of GDP growth and a negative impact of unemployment on the death rate in the next year is consistent with our results and indicates a procyclical oscillation of mortality.

In summary, we believe the results of Gerdtham and Johannesson (2005) are much less reliable than ours because insufficient consideration for lagged effects, use of unreliable business-cycle indicators, data collected during a very short period in terms of business cycles, and lack of power to detect effects due to few deaths in their sample.

We performed some analyses using the Swedish regional data used by Svensson (2007, 2010). We reproduced his results in several specifications of panel regressions. Then we reanalyzed this data, detrending the mortality and the unemployment regional data by either subtracting an HP trend $(\gamma=100)$ or by converting variables into first differences. We investigated models of the form

$$
\mathrm{d} M_{r, t}=\alpha+\beta_{i} \cdot \sum_{i=0}^{k} \mathrm{~d} U_{r, t-i}+\varepsilon_{r, t}+\psi_{t}
$$

where $\mathrm{d} M_{r, t}$ is detrended mortality of region $r$ at year $t, \mathrm{~d} U_{r, t-i}$ is detrended unemployment for region $r$ at year $t-i, \varepsilon_{r, t}$ is a normally distributed error term, and $\psi_{t}$ is a normally distributed random effect for year. This random effect (Venables and Ripley 2002) adjusts for the spatial autocorrelation between regions (Layne 2007). To explore lagged effects we estimated models for $k=0, k=1, k=2, k=3$ and for each dependent variable we chose the model minimizing AIC. The best fit in terms of AIC was obtained when the model included effects at lags zero and one, or at lag zero only (table 7). However, for some mortality rates, AIC is minimized in specifications including lags zero to two, or even lags zero to three. This and the effects with alternating sign that are difficult to explain makes some of these results puzzling, revealing the complexities of interpreting lag regression models. At any rate, what these regional models show is that negative and often statistically significant effects of re- 
gional unemployment predominate at lags zero or one, for total mortality and for sexspecific mortality, indicating a procyclical fluctuation of total and sex-specific mortality. With very few qualifications the same can be said for mortality at ages $45^{-64}$ and 65 and over, as well as traffic mortality. However, for ischemic heart disease mortality positive effects that predominate at lags zero and two make the interpretation of these effects equivocal.

Considering all the results of regressions with regional data, ${ }^{12}$ we interpret the negative signs of the predominant effects at lag one as evidence consistent with our analysis of national data indicating a procyclical oscillation of total, male and female mortality, as well as mortality at the three specific ages that Svensson investigated. We believe that Svensson's analysis of regional data missed the procyclical oscillation of death rates primarily because he did not consider lagged effects. In addition, his panel methods (including fixed effects for year, and sometimes region-specific linear trends too) could be less statistically powerful than our random effect specification.

\section{General Discussion}

The procyclical fluctuation of national Swedish mortality rates revealed by the results in earlier sections is consistent with results from other industrialized countries; it is based on the period 1968-2003, which included eight or nine macroeconomic fluctuations; it is found in total, male, and female mortality, as well as age-specific mortality for most age groups; it is revealed by the correlations of mortality with seven economic indicators and also by lag models in which health indicators are regressed on an economic indicator; and, finally, it is consistent with the procyclical fluctuation of total and age-specific mortality rates (and the countercyclical fluctuation of life expectancy at birth) found by Tapia Granados and Ionides (2008) in time series for the second half of the $20^{\text {th }}$ century. In contrast, the countercyclical

\footnotetext{
${ }^{12}$ In regional panel models not including a random effect for year, the unemployment effects were greater in size and much more significant than those reported in table 7 . However, we consider them probably biased by spatial autocorrelation.
} 
fluctuation of mortality reported by Gerdtham and Johannesson (2005) is inconsistent with other recent results from industrialized countries; is observed only for male mortality; appears only for selected business cycle indicators (some of questionable validity); and is sensitive to the inclusion of lagged terms in the regressions, or to the change in the time frame considered, often appearing only when the time frame is restricted to the expansionary years 1981-1991. Moreover, with regional data, Svensson $(2007,2008)$ was unable to reproduce Gerdtham and Johannesson's finding of a countercyclical fluctuation of male mortality, while our reanalysis of Svensson's regional data produced results that are basically consistent with the other results presented in this paper, as well as with the results in Tapia Granados and Ionides (2008). Considering all the evidence, it must be concluded that in recent decades total mortality in Sweden, as well as male and female mortality individually, have oscillated procyclically.

CVD is the first cause of death in most countries and in Sweden about half of all death are attributed to this cause. CVD deaths have been found to be strongly procyclical at lag zero in the United States (Ruhm 2000; Tapia Granados 2005b), Germany (Neumayer 2004), and the OECD countries as a group (Gerdtham and Ruhm 2006), while in Spain they were found to be very slightly procyclical (Tapia Granados 2005). In Sweden, the lag-zero correlations of CVD mortality with economic indicators (table 4) do not reveal a comovement of both, but lag regression models indicate a predominantly positive net effect of GDP growth at lags zero and one on this type of mortality (table 6). Therefore, overall CVD mortality in Sweden tends to rise in expansions, procyclically. The same pattern is observed for stroke mortality at all ages, or at ages below 65 (table 6, panel B), though for ages 65-74 the preferred model only includes a positive effect at lag zero, what implies a countercyclical oscillation of stroke mortality at these ages.

Findings for ischemic heart disease are much more difficult to interpret. When modeled in lag regressions at the national level (table 6, panel B) ischemic heart disease mortality reveals predominantly positive effects of GDP at lag one. This suggests a procyclical fluctuation, with heart attacks fluctuating upward one year after the start of an expansion 
and fluctuating downward one year after the start of a recession. However, in regional regression models (table 7) positive effects of unemployment at lags zero and two predominate and cross-correlation analyses of national data also suggest positive effects of unemployment, i.e. countercyclical effects, on ischemic heart disease mortality at ages 65 and over (table 4). But most fatal heart attacks (i.e., deaths attributed to ischemic heart disease) occur at advanced age. Additional work is needed to better identify the effects of the economy on ischemic heart disease mortality and why it may oscillate differently than other causes.

In our findings traffic injury mortality correlates strongly with the business cycle at lag zero (figure 3), particularly at young and middle ages (table 4). Regression models in which the change in traffic mortality is regressed on coincidental and lagged GDP growth (table 6, panel B, bottom) also reveal this procyclical oscillation of traffic mortality at all ages and for males, but at specific ages the regression coefficients are indistinguishable from zero and in panel models with regional data (table 7) marginally significant effects appear at lag three. Two factors may explain these results. First, the differencing of a time series, converting it into a rate of change or a first difference series, largely filters out the fluctuations in business-cycle frequencies. This can result in failure to detect relations between variables at the business-cycle frequencies (Baxter and King 1999) and is one of the reasons for the increasing use of the HP filter and other detrending procedures instead of differencing. Second, strong associations at a larger level of aggregation (at all ages or at the national level) may weaken when mortality is disaggregated (by age strata or by regions) because of the introduction of statistical noise.

The strongly procyclical character of CVD mortality in general (Ruhm 2000, Tapia Granados 2005) and heart attack mortality in the United States for all ages (Ruhm 2008) contrasts with the absence of a clear procyclical oscillation in ischemic heart disease mortality reported here and elsewhere (Svensson 2007) for Sweden. It has been previously proposed that the Swedish welfare state-with labor regulations and a labor market more friendly for employees than in the United States-could be a factor in explaining a lower im- 
pact of macroeconomic fluctuations on health in Sweden (Gerdtham and Ruhm 2006;

Ruhm 2006; Svensson 2007) and this hypothesis deserves further investigation.

It is plausible that differences between institutional regulations of working conditions and labor markets between Sweden and the United States may perhaps account for the differential busyness-cycle dynamics of CVD mortality in both countries. The index of average hours worked in manufacturing has long been considered a leading business cycle indicator (Mitchell 1951). Early in expansions firms demand overtime from workers and tend to hold off on hiring additional workers until managers are confident that demand is growing. Then average hours will increase early in an expansion and then will decrease. Similarly, early in a recession employers will reduce hours worked to reduce output and costs, and average hours will go down, but if the slowdown deepens into a recession, layoffs eventually will raise average hours. Differences in the ability of firms to hire and fire workers easily, or demand overtime from employees may well account for the fact that the index of average hours in manufacturing is procyclical in the United States and countercyclical in Sweden. The countercyclical character of this index, if present in other OECD economies-in many European countries mandatory overtime does not exist and there are generally more limitations for freely firing workers than in the United States (Chung 2007) - might explain why Johansson (2004), while getting results indicating an increase of mortality in periods of economic expansion, finds that an increase in hours worked per employed person significantly decreases the mortality rate in a sample of 23 OECD countries during 1960-1997.

In this Swedish sample HP-detrended infant mortality significantly correlates negative with detrended unemployment (tables 1 and 3) and first differences in GDP growth have a marginally significant positive effect on infant mortality at lag one (table 6), all of which suggest a procyclical oscillation of infant deaths. Potential pathways for procyclical infant mortality were mentioned in section 3. On the other hand, since traffic-related deaths are intensely procyclical and a major cause of mortality in adolescents and young adults (table 4), they are a very likely cause of the procyclical oscillation of deaths at ages 10-19 (tables 1 and 2). 
We report only bivariate models. Therefore, our results can be challenged on the

grounds of potential bias due to omitted variables. However, results based on the analyses of economic indicators covering a number of business cycles and converted into stationary series by filtering or differencing make it very unlikely that omitted variables may significantly bias the results with respect to business cycle fluctuations. Indeed, many variables change together with the levels of economic activity (for instance, overtime, average levels of daily sleep, volume of road traffic, atmospheric pollution, etc.), and these are exactly the candidate intermediary factors connecting "the economy" with the health outcomes. It is difficult to imagine real omitted variables that are not an intrinsic part of the aggregate fluctuations of economic activity indexed in this study by variables such as unemployment or GDP. A lurking variable seriously biasing the present results might be, for instance, technological changes having an immediate or short-lagged contractionary effect on mortality, and appearing or being implemented population-wide late in each expansion or early in each recession, inducing in this way a procyclical oscillation of mortality. But this kind of technological innovation is hard to imagine, and it is even harder to believe that it would have such an intense effect on mortality fluctuations (McKinlay et al., 1989).

Results of this investigation can also be challenged on the basis of criticisms of methods of detrending in general, the HP filter in particular, or the use of $\gamma=100$ when dealing with annual data (Ashley and Verbrugge 2006; Baxter and King 1999; Dagum and Giannerini 2006). However, the HP filter is now a standard method for detrending economic data (Ravn and Uhlig 2002), and $\gamma=100$ is very regularly used with yearly observations and is the default value for annual data in econometric software packages. Furthermore, our overall conclusions are robust to variations in the choice of $\gamma$ (for additional discussion of the choice of $\gamma$, see Appendix A). Contrary to the view that HP-filtering introduces businesscycle frequency fluctuations in the data, so that the computed correlations between HPdetrended series are just "discovering” a spurious artifactual pulsation introduced by the filter, in this investigation, cross-correlations and distributed lag models with variables either HP-detrended or differenced produced similar qualitative results, revealing procyclical oscil- 
lations of death rates. Panel regressions (Neumayer 2004; Ruhm 2000; Ruhm 2005b; Tapia Granados 2005a) and analysis of time series (Laporte 2004, Tapia Granados 2005b) have produced exactly the same conclusion when they were applied in the past to study the relation between macroeconomic change and mortality in the United States

Based on the results of a number of statistical models reported here as well as our examination of the results of other investigations, we conclude that in Sweden mortality of both males and females oscillated procyclically during recent decades. Since the long-term trend of age-adjusted mortality rates is a falling one, its procyclical oscillation means that age-adjusted mortality declines in recessions, while during expansions it declines less rapidly, or even increases. The fact that even in a country like Sweden, with a highly developed system of social services and publicly financed health care, mortality tends to evolve for the worse during economic expansions must be a warning call about the unintended consequences of economic growth. ${ }^{13}$ The policy implications of procyclical mortality are too broad to be discussed here, but a clear implication is the need to further study the pathways connecting the fluctuations of the economy with the oscillations of death rates. Knowledge of these mechanisms may lead to the development of policies to reduce the harmful effects of macroeconomic fluctuations on health.

13 The potentially harmful consequences of economic growth for social welfare were already discussed decades ago from a variety of perspectives, for instance by Mishan (1970), Hirsch (1976), Daly (1977), Zolotas (1981), and Eyer (1984). Georgescu-Roegen (1976, 1971; Randolph Beard and Lozada 1999) presented a comprehensive view of the bioenvironmental implications of the exponential growth of the economy. 
Table 1. Cross-correlations between three economic indicators, life expectancy, and selected mortality rates for Sweden, 1968-2003

\begin{tabular}{|c|c|c|c|}
\hline Health indicator & Unemployment & GDP & $\begin{array}{c}\text { Average hours in } \\
\text { manufacturing }\end{array}$ \\
\hline Life expectancy & $0.35^{*}$ & -0.15 & $0.51^{* *}$ \\
\hline LE, males & $0.37^{*}$ & -0.18 & $0.48^{* *}$ \\
\hline LE, females & $0.30^{\dagger}$ & -0.10 & $0.49^{* *}$ \\
\hline ASMR, all ages & -0.27 & 0.21 & $-0.49^{*}$ \\
\hline ASMR, males & -0.19 & 0.12 & $-0.37^{*}$ \\
\hline ASMR, females & $-0.31^{\dagger}$ & 0.26 & $-0.38^{*}$ \\
\hline Crude mortality rate & -0.24 & 0.11 & $-0.39^{*}$ \\
\hline CMR, males & -0.17 & 0.08 & $-0.37^{*}$ \\
\hline CMR, females & -0.27 & 0.14 & $-0.38^{*}$ \\
\hline \multicolumn{4}{|c|}{ Age-specific mortality rates } \\
\hline Infant mortality & $-0.41^{*}$ & 0.24 & -0.16 \\
\hline $0-4$ & $-0.48^{* *}$ & $0.36^{*}$ & $-0.34^{*}$ \\
\hline $5-9$ & -0.01 & -0.08 & $-0.34^{*}$ \\
\hline $10-19$ & $-0.42^{* *}$ & $0.52^{* *}$ & -0.12 \\
\hline $20-44$ & $-0.42^{* *}$ & $0.36^{*}$ & -0.21 \\
\hline $25-64$ & $-0.30^{\dagger}$ & 0.17 & $-0.34^{*}$ \\
\hline $45^{-64}$ & -0.25 & 0.11 & $-0.33^{*}$ \\
\hline $55^{-64}$ & -0.26 & 0.07 & $-0.42^{* *}$ \\
\hline $65-84$ & -0.03 & -0.13 & $-0.37^{*}$ \\
\hline 85 and over & 0.16 & -0.19 & -0.10 \\
\hline
\end{tabular}

Notes: Correlations with mortality rates are based on $n=36$ or close to 36 in most cases; in life expectancy correlations, $n=32$. ASMR is age-standardized mortality rate. All variables detrended with the Hodrick-Prescott filter, $\gamma=100$.

$+P<0.1 * P<0.05 * * P<0.01$ 
Table 2. Cross-correlation between economic indicators and age- and sex-specific mortality rates for large age strata. In each of the two panels, the series are either in rate of change or HP-detrended.

\begin{tabular}{|c|c|c|c|}
\hline $\begin{array}{l}\text { Age- } \\
\text { specific } \\
\text { mortality } \\
\end{array}$ & Unemployment rate & GDP & Average hours in manufacturing \\
\hline \multicolumn{4}{|c|}{ A.-Series in rate of change } \\
\hline \multicolumn{4}{|c|}{ Male mortality } \\
\hline $10-19$ & -0.09 & 0.15 & -0.04 \\
\hline $20-44$ & -0.08 & 0.05 & -0.04 \\
\hline $45^{-64}$ & -0.06 & 0.11 & $-0.56^{* *}$ \\
\hline $65-84$ & 0.27 & -0.23 & $-0.30^{\dagger}$ \\
\hline 85 \& over & 0.09 & -0.13 & -0.08 \\
\hline \multicolumn{4}{|c|}{ Female mortality } \\
\hline $10-19$ & -0.16 & 0.15 & -0.10 \\
\hline $20-44$ & -0.19 & 0.20 & -0.14 \\
\hline $45-64$ & -0.19 & 0.24 & 0.00 \\
\hline $65-84$ & 0.10 & -0.23 & -0.16 \\
\hline 85 \& over & 0.18 & -0.20 & -0.19 \\
\hline \multicolumn{4}{|c|}{ B. $-H P-$ detrended series } \\
\hline \multicolumn{4}{|c|}{ Male mortality } \\
\hline $10-19$ & $-0.41^{*}$ & $0.50^{*}$ & -0.04 \\
\hline $20-44$ & $-0.42^{*}$ & $0.31^{\dagger}$ & -0.17 \\
\hline $45^{-64}$ & -0.14 & 0.01 & $-0.38^{*}$ \\
\hline $65-84$ & 0.06 & -0.16 & $-0.28 \dagger$ \\
\hline 85 \& over & 0.21 & -0.17 & 0.07 \\
\hline \multicolumn{4}{|c|}{ Female mortality } \\
\hline $10-19$ & $-0.28^{\dagger}$ & $0.34^{*}$ & -0.20 \\
\hline $20-44$ & $-0.30^{\dagger}$ & $0.31^{\dagger}$ & -0.19 \\
\hline $45^{-64}$ & $-0.31^{\dagger}$ & 0.20 & -0.15 \\
\hline $65-84$ & -0.11 & -0.08 & $-0.40^{*}$ \\
\hline 85 \& over & 0.05 & -0.14 & -0.21 \\
\hline
\end{tabular}

$\dagger P<0.1 * P<0.05 * * P<0.01$ 
Table 3. Split sample cross-correlations of economic indicators with selected mortality rates and life expectancy

\begin{tabular}{|c|c|c|c|}
\hline Health indicator & Unemployment & GDP & $\begin{array}{c}\text { Average hours in } \\
\text { manufacturing }\end{array}$ \\
\hline \multicolumn{4}{|c|}{ A. Sample 1968-1989 $(n=22)$} \\
\hline Life expectancy & 0.22 & 0.04 & $0.38 \dagger$ \\
\hline Males & 0.27 & 0.06 & $0.37^{\dagger}$ \\
\hline Females & 0.16 & 0.01 & 0.35 \\
\hline Crude mortality rate & -0.16 & 0.06 & -0.29 \\
\hline Males & -0.07 & 0.01 & -0.23 \\
\hline Females & -0.22 & 0.09 & $-0.34^{\dagger}$ \\
\hline Infant mortality & 0.30 & -0.09 & $0.46^{*}$ \\
\hline Mortality $10-19$ & $-0.47^{*}$ & $0.69^{* * *}$ & 0.16 \\
\hline Mortality 20-44 & $-0.61^{* *}$ & $0.41^{*}$ & -0.27 \\
\hline Mortality $45-64$ & 0.11 & -0.24 & -0.32 \\
\hline Mortality $65-84$ & 0.07 & -0.18 & -0.32 \\
\hline Mortality 85 \& over & 0.09 & -0.20 & -0.26 \\
\hline \multicolumn{4}{|c|}{ B. Sample 1989-2003 $(n=15)$} \\
\hline Life expectancy ${ }^{a}$ & 0.53 & -0.29 & $0.73^{*}$ \\
\hline Males $^{\mathrm{a}}$ & $0.61^{\dagger}$ & -0.39 & $0.69^{*}$ \\
\hline Females $^{a}$ & 0.44 & -0.17 & $0.74^{*}$ \\
\hline Crude mortality rate & -0.20 & 0.01 & $-0.44^{\dagger}$ \\
\hline Males & -0.10 & -0.08 & $-0.45^{\dagger}$ \\
\hline Females & -0.25 & 0.07 & -0.39 \\
\hline Infant mortality & $-0.78^{* * *}$ & $0.51^{\dagger}$ & $-0.68^{* *}$ \\
\hline Mortality $10-19$ & $-0.50^{\dagger}$ & $0.46^{\dagger}$ & -0.39 \\
\hline Mortality 20-44 & $-0.50^{\dagger}$ & $0.47^{\dagger}$ & -0.24 \\
\hline Mortality $45-64$ & -0.30 & 0.18 & -0.22 \\
\hline Mortality $65-84$ & 0.06 & -0.28 & -0.34 \\
\hline Mortality 85 \& over & 0.36 & -0.28 & 0.12 \\
\hline \multicolumn{4}{|c|}{ C. Sample 1981-1992 $(n=11)$} \\
\hline Life expectancy & 0.53 & 0.40 & $-0.37^{\dagger}$ \\
\hline Males & $0.59^{\dagger}$ & 0.49 & $-0.33^{\dagger}$ \\
\hline Females & 0.45 & 0.30 & -0.40 \\
\hline Crude mortality rate & -0.28 & 0.25 & -0.10 \\
\hline Males & -0.18 & 0.17 & -0.01 \\
\hline Females & -0.36 & 0.31 & $-0.17^{\dagger}$ \\
\hline Infant mortality & -0.41 & 0.15 & $0.46^{*}$ \\
\hline Mortality 10-19 & $-0.82^{* *}$ & $0.85^{* *}$ & -0.31 \\
\hline Mortality 20-44 & $-0.72^{* *}$ & $0.82^{* *}$ & -0.11 \\
\hline Mortality $45-64$ & 0.39 & -0.41 & 0.15 \\
\hline Mortality $65-84$ & -0.05 & -0.08 & -0.15 \\
\hline Mortality $85 \&$ over & 0.21 & -0.27 & -0.18 \\
\hline
\end{tabular}

Notes: All variables detrended with the Hodrick-Prescott filter, $\gamma=100$. 
Table 4. Correlations between economic indicators and cause-specific mortality rates for the years 1968-2002 in Sweden.

\begin{tabular}{|c|c|c|c|}
\hline Mortality rate & $\begin{array}{c}\text { Unemploy- } \\
\text { ment }\end{array}$ & GDP & $\begin{array}{l}\text { Average hrs. in } \\
\text { manufacturing }\end{array}$ \\
\hline $\begin{array}{l}\text { Cardiovascular disease } \\
\text { ( Ioo-I99) }^{\mathrm{a}}\end{array}$ & 0.14 & -0.17 & -0.14 \\
\hline Males & 0.19 & -0.13 & -0.10 \\
\hline Females & 0.06 & -0.11 & -0.16 \\
\hline Ages 55-64 males & -0.02 & -0.15 & -0.18 \\
\hline Ages 55-64 females & -0.16 & 0.06 & 0.05 \\
\hline Ages $65-74$ males & 0.21 & -0.22 & -0.16 \\
\hline Ages $65-74$ females & 0.13 & -0.15 & -0.17 \\
\hline Ages $75-84$ & 0.01 & -0.09 & -0.15 \\
\hline $\begin{array}{l}\text { Ischemic heart disease } \\
\left(\mathrm{I} 20-\mathrm{I}_{25}\right)^{\mathrm{a}}\end{array}$ & $0.28{ }^{\dagger}$ & -0.29 & -0.10 \\
\hline Males & 0.27 & -0.28 & -0.03 \\
\hline Females & 0.27 & -0.29 & -0.19 \\
\hline Ages 25-64 males & 0.05 & -0.10 & -0.02 \\
\hline Ages 25-64 females & $-0.37^{*}$ & 0.26 & -0.18 \\
\hline Ages 35-44 males & 0.15 & -0.23 & 0.09 \\
\hline Ages $35-44$ females & $-0.34^{*}$ & 0.27 & -0.19 \\
\hline Ages 45-54 males & 0.11 & -0.05 & -0.02 \\
\hline Ages $45-54$ females & -0.26 & 0.19 & -0.24 \\
\hline Ages 55-64 males & -0.01 & -0.07 & -0.04 \\
\hline Ages $55-64$ females & -0.24 & 0.16 & -0.05 \\
\hline Ages 65 and older & $0.33^{\dagger}$ & $-0.32^{\dagger}$ & -0.10 \\
\hline Ages 65 and older males & $0.32^{\dagger}$ & -0.29 & -0.04 \\
\hline Ages 65 and older females & $0.33^{\dagger}$ & $-0.32^{*}$ & -0.17 \\
\hline Ages 85 and older & $0.39^{*}$ & $-0.36^{*}$ & 0.00 \\
\hline $\begin{array}{l}\text { Cerebrovascular disease } \\
\text { (stroke, I6o-I69) }^{\mathrm{a}}\end{array}$ & -0.16 & 0.13 & -0.18 \\
\hline Ages 25-64 & -0.08 & 0.03 & -0.17 \\
\hline Ages 25-64 males & 0.01 & -0.14 & $-0.33^{*}$ \\
\hline Ages 25-64 females & 0.05 & 0.03 & 0.09 \\
\hline Ages 65-74 & 0.07 & 0.06 & -0.19 \\
\hline Ages 65-74 males & 0.21 & -0.22 & -0.16 \\
\hline Ages $65-74$ females & 0.13 & -0.15 & -0.17 \\
\hline $\begin{array}{l}\text { Traffic-related mortality } \\
(\text { V01-V99) }\end{array}$ & $-0.67^{* * *}$ & $0.69^{* * *}$ & -0.27 \\
\hline Males & $-0.53^{* *}$ & $0.58^{* *}$ & -0.21 \\
\hline Females & $-0.51^{* *}$ & $0.50^{* *}$ & $-0.30^{\dagger}$ \\
\hline Ages $15^{-24}$ & $-0.65^{* * *}$ & $0.68^{* * *}$ & -0.10 \\
\hline Ages 25-34 & $-0.53^{* *}$ & $0.39^{*}$ & $-0.46^{* *}$ \\
\hline Ages $35-44$ & -0.17 & 0.19 & -0.12 \\
\hline Ages $45-54$ & $-0.57^{* * *}$ & $0.60^{* * *}$ & -0.25 \\
\hline Ages $55^{-64}$ & $-0.40^{*}$ & $0.41^{*}$ & -0.29 \\
\hline Ages $65-74$ & -0.21 & 0.24 & -0.02 \\
\hline Ages $75-84$ & -0.24 & 0.25 & 0.02 \\
\hline
\end{tabular}

Notes: $n=32$ or close to 32 for each correlation model. Variables detrended with the HP filter, $\gamma=100$. Age-standardized death rates from the WHO-Europe HFA Database.

a Codes according to the International Classification of Diseases, $10^{\text {th }} \mathrm{ed}$. (ICD10). 
Table 5. Parameter estimates in models with a health indicator in first differences regressed on a constant, and coincidental and lagged values-except in panel $\mathrm{C}-$ of an economic indicator

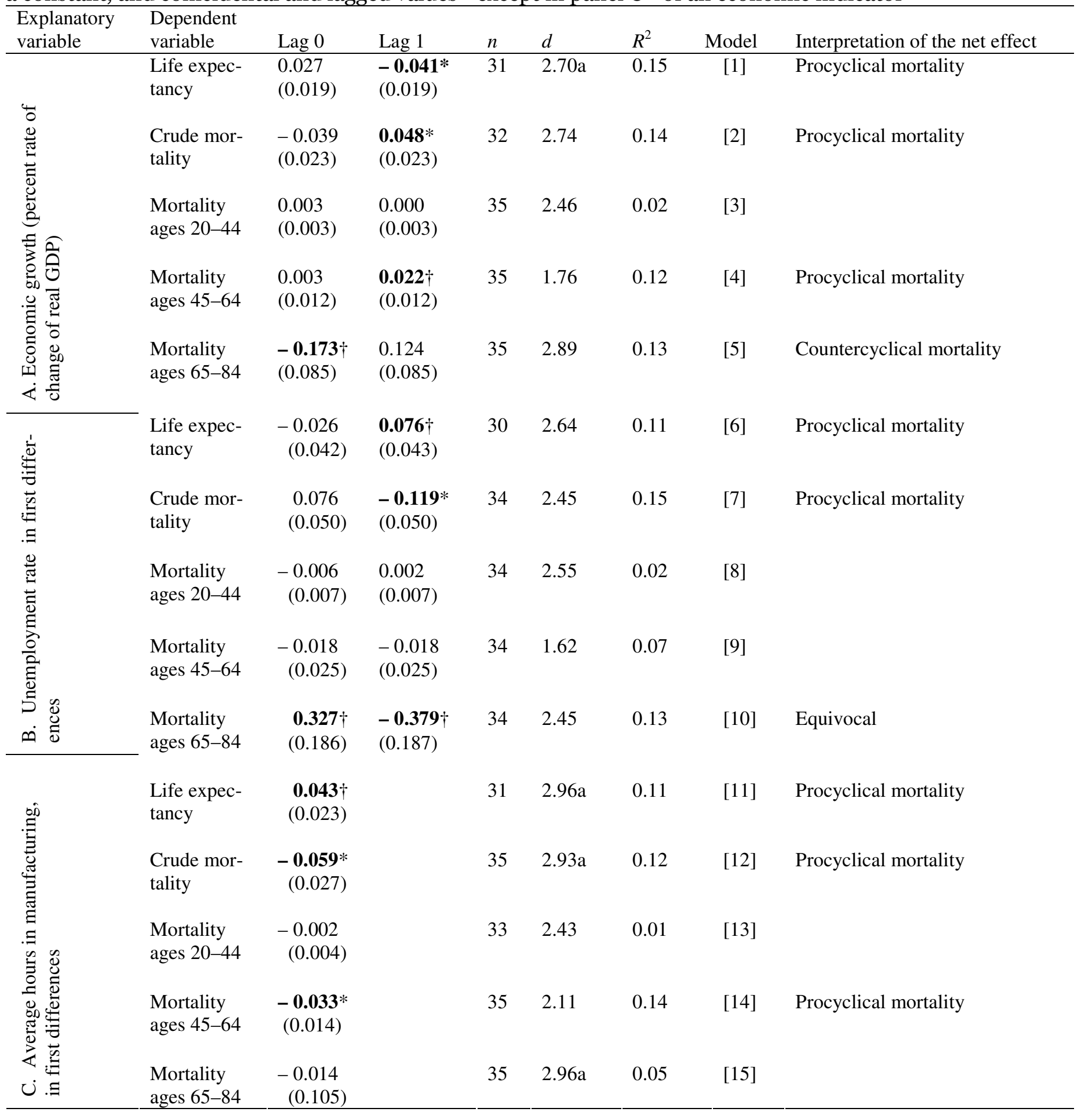

$\dagger P<0.1 * P<0.05{ }^{\mathrm{a}} P<0.05$ for the null hypothesis of no negative autocorrelation of the error term.

Notes: Standard errors in parentheses. Data include years from 1968 to the early 2000s. Estimates statistically significant at a confidence level of $90 \%$ or higher are highlighted in boldface. Mortality rates are measured in deaths per 1,000 population, life expectancy in years. In similar models using age-specific mortality for ages 85 and over the 'best' model was the one including just the lag-zero effect, but the parameter estimates and its standard errors were approximately of the same size- that is, the effect was indistinguishable from zero- and the $R^{2}$ was $6 \%$ or lower. 
Table 6. Regression estimates of the coincidental and lagged effect of GDP growth on the annual change in age-standardized mortality rates in models minimizing AIC among models including just lag zero, lags zero and one, or lags zero to two

\begin{tabular}{|c|c|c|c|c|c|c|}
\hline \multirow{2}{*}{$\begin{array}{l}\text { Mortality rate } \\
\text { A. General mortality }\end{array}$} & \multicolumn{2}{|l|}{ Lag o } & \multicolumn{2}{|c|}{$\operatorname{Lag} 1$} & \multirow[t]{2}{*}{$\operatorname{Lag} 2$} & \multirow[t]{2}{*}{$\begin{array}{l}\text { Oscillation of mortality ac- } \\
\text { cording to the net effect }\end{array}$} \\
\hline & & & & & & \\
\hline All ages & -0.97 & & $3 \cdot 35$ & $*$ & & Procyclical \\
\hline Males & -1.86 & & 4.68 & * & & Procyclical \\
\hline Females & -0.36 & & 2.38 & + & & Procyclical \\
\hline Infant mortality $($ age $<1)$ & -0.04 & & 0.06 & + & & Procyclical \\
\hline \multicolumn{7}{|l|}{ Ages 25-64 } \\
\hline Males & -0.34 & & 1.65 & $*$ & & Procyclical \\
\hline Females & 1.05 & + & & & & Procyclical \\
\hline \multicolumn{7}{|l|}{ B. Cause-specific mortality } \\
\hline \multicolumn{7}{|l|}{ Cardiovascular disease } \\
\hline All ages & -1.45 & & 2.16 & * & & Procyclical \\
\hline Ages 0-64 & -0.34 & & 0.56 & $* *$ & & Procyclical \\
\hline Ages $45-54$ & -0.15 & & 0.59 & & & Procyclical \\
\hline Ages $55-64$ & -1.67 & & 2.71 & $*$ & & Procyclical \\
\hline Ages 65-74 & -1.83 & & & & & Countercyclical \\
\hline Ages $75-84$ & -15.80 & & 26.08 & $*$ & -13.85 & Equivocal \\
\hline \multicolumn{7}{|l|}{ Ischemic heart disease } \\
\hline All ages & -0.95 & & 1.65 & * & & Procyclical \\
\hline Males & -1.98 & & 3.45 & $*$ & -2.03 & Equivocal \\
\hline Females & -0.69 & & 1.08 & $*$ & & Procyclical \\
\hline Ages 25-64 & -0.19 & & 0.62 & $*$ & & Procyclical \\
\hline Males & -0.45 & & 0.94 & + & & Procyclical \\
\hline Females & 0.07 & & 0.30 & + & & Procyclical \\
\hline Ages $65^{+}$ & -7.70 & & 11.96 & + & & Procyclical \\
\hline Ages $85^{+}$ & -57.47 & & $81.72^{*}$ & & -47.04 & Equivocal \\
\hline \multicolumn{7}{|c|}{ Cerebrovascular disease (stroke) } \\
\hline All ages & -0.10 & & 0.46 & * & & Procyclical \\
\hline Ages 25-64 & -0.16 & & 0.30 & $* *$ & & Procyclical \\
\hline Ages $65-74$ & 0.30 & & & & & Countercyclical \\
\hline \multicolumn{7}{|l|}{ Traffic injuries } \\
\hline All ages & 0.15 & $*$ & & & & Procyclical \\
\hline Males & 0.20 & $*$ & & & & Procyclical \\
\hline Females & 0.10 & & & & & Procyclical \\
\hline Ages $15-24$ & 0.28 & & & & & Procyclical \\
\hline Ages 25-34 & 0.00 & & & & & \\
\hline Ages $35-44$ & 0.08 & & & & & Procyclical \\
\hline Ages $45-54$ & 0.13 & & & & & Procyclical \\
\hline Ages $55-64$ & 0.22 & & & & & Procyclical \\
\hline Ages $65-74$ & 0.46 & + & -0.32 & & & Procyclical \\
\hline Ages $75-84$ & 0.09 & & & & & Procyclical \\
\hline
\end{tabular}


Table 7. Effects of the regional unemployment rate on regional mortality in lag regression models. For each dependent variable (mortality rate) the lag specification selected is that minimizing AIC out of the four possible lag lengths

\begin{tabular}{|c|c|c|c|c|}
\hline \multicolumn{5}{|c|}{ A. Percentage change in mortality regressed on differenced regional unemployment } \\
\hline Mortality rate & Lag 0 & Lag 1 & Lag 2 & Lag 3 \\
\hline Total mortality & 0.05 & $-0.36 \dagger$ & & \\
\hline Male mortality & 0.36 & $-0.66^{* *}$ & & \\
\hline Female mortality & -0.21 & & & \\
\hline Age-or cause-specifi & & & & \\
\hline Ages $20-44$ & -0.47 & & & \\
\hline Ages $45^{-64}$ & 0.08 & -0.56 & & \\
\hline Ages $65^{+}$ & 0.08 & $-0.40^{\dagger}$ & & \\
\hline Ischemic heart disease & 0.72 & -0.57 & $1.00^{*}$ & \\
\hline Traffic injuries & -2.65 & 1.29 & $-5 \cdot 59^{* *}$ & $3.40^{\dagger}$ \\
\hline
\end{tabular}

B. Regional mortality and regional unemployment as HP-detrended series, $\gamma=100$

\begin{tabular}{lcccc}
\hline & Lag 0 & Lag 1 & Lag 2 & Lag 3 \\
\hline Total mortality & -0.14 & $-3.73^{*}$ & & \\
Male mortality & $3.88^{\dagger}$ & $-8.29^{* *}$ & 1.99 & $3.98^{\dagger}$ \\
Female mortality & $-3.69^{\dagger}$ & & & \\
$\quad$ Age - or cause-specific mortality & & & & \\
Ages 20-44 & -0.90 & 0.70 & $-1.34^{*}$ & \\
Ages 45-64 & 2.73 & $-4.59^{*}$ & & \\
Ages 65+ & 3.31 & $-18.18^{\dagger}$ & & \\
Ischemic heart disease & $2.80^{*}$ & -2.27 & $4.36^{* *}$ & \\
Traffic injuries & $-0.20^{\dagger}$ & & & \\
\hline Notes $+P<0.1 * P<0.05 * * P<0.01$ & &
\end{tabular}

Notes: $\dagger P<0.1 \quad * P<0.05 \quad * * P<0.01$.

Data for the years 1980-2005, in 21 Swedish regions. Models including a random effect for each year, to adjust for the spatial autocorrelation of the regional mortality rates. Heteroskedasticity over space in the panel regression was successfully stabilized by weighting regional observations by the square root of the population size. 
Figure 1. Selected variables used in the study. The thin curves are Hodrick-Prescott trends computed with a smoothing parameter $\gamma=100$

Real GDP

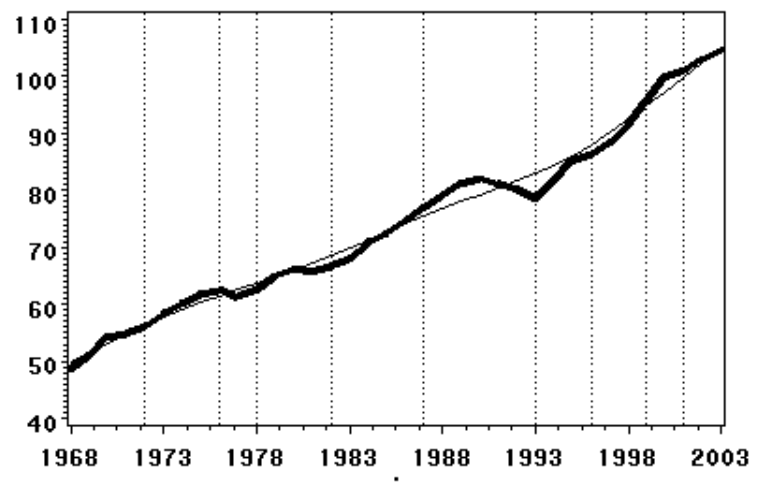

Average hours in manufacturing

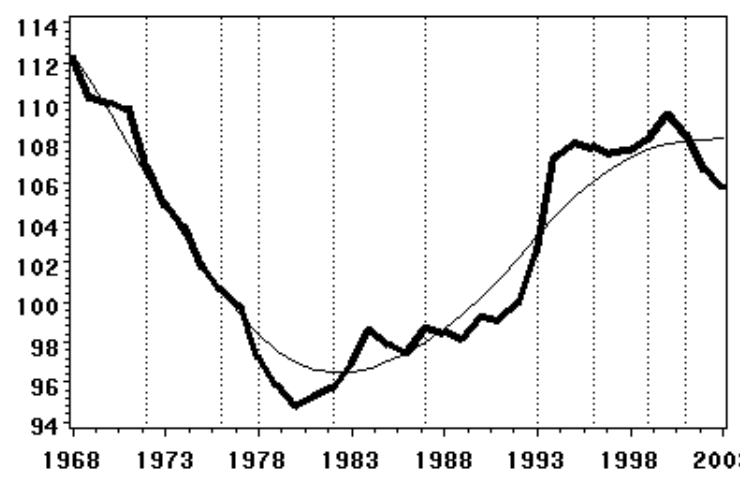

Age-adjusted mortality

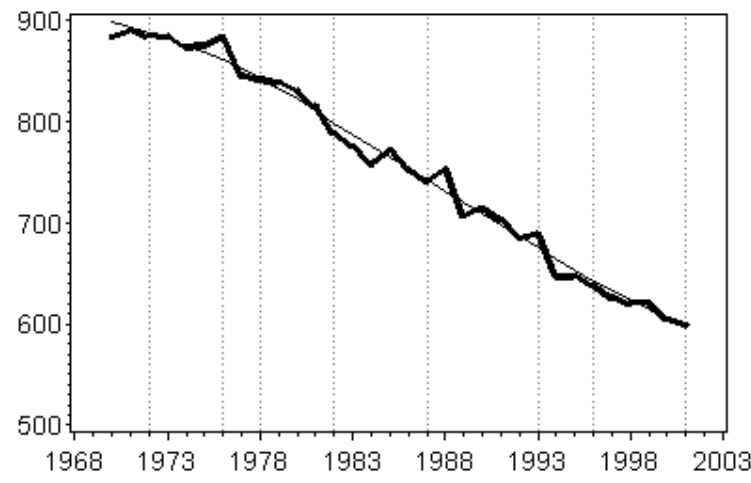

Mortality ages 20-44

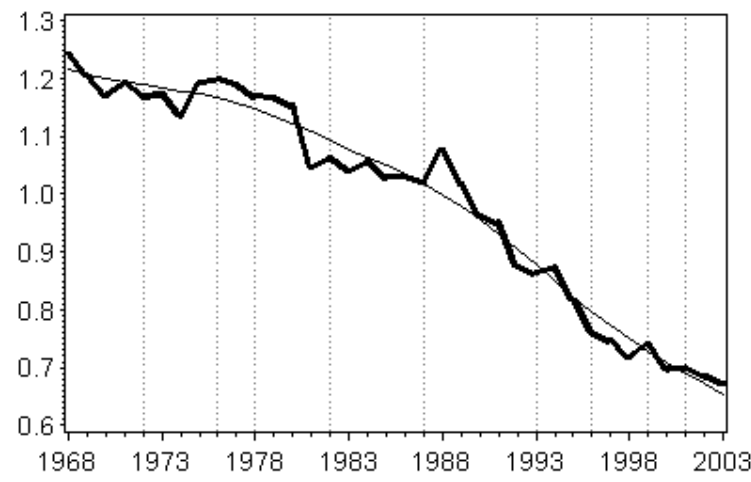

Unemployment rate (\%)

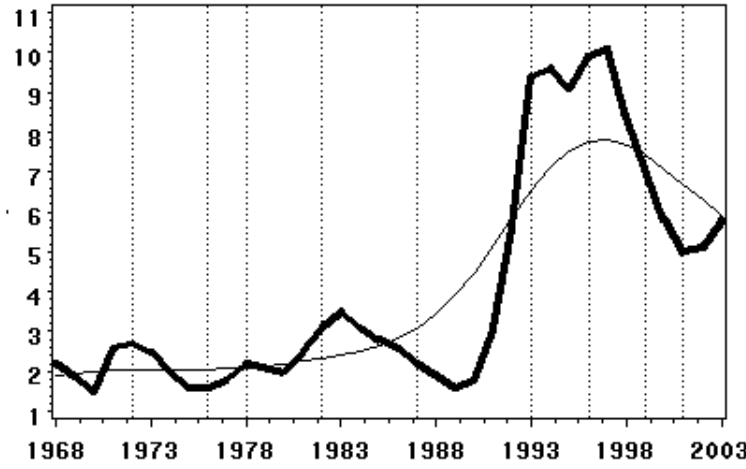

Life expectancy at birth

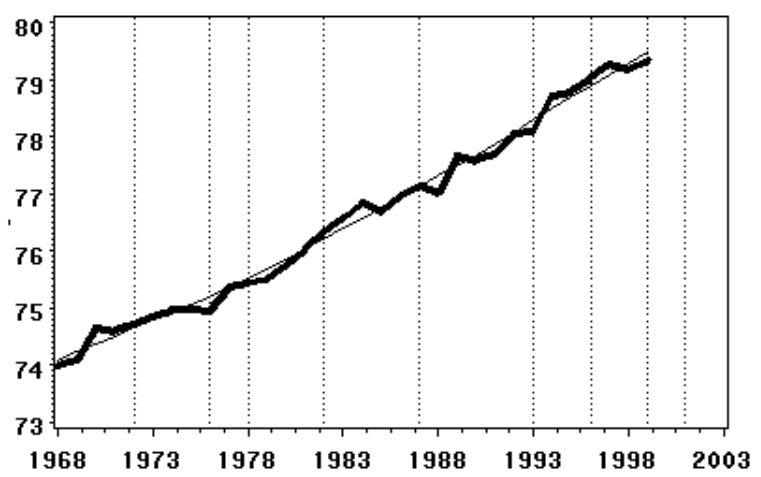

Mortality ages 10-19

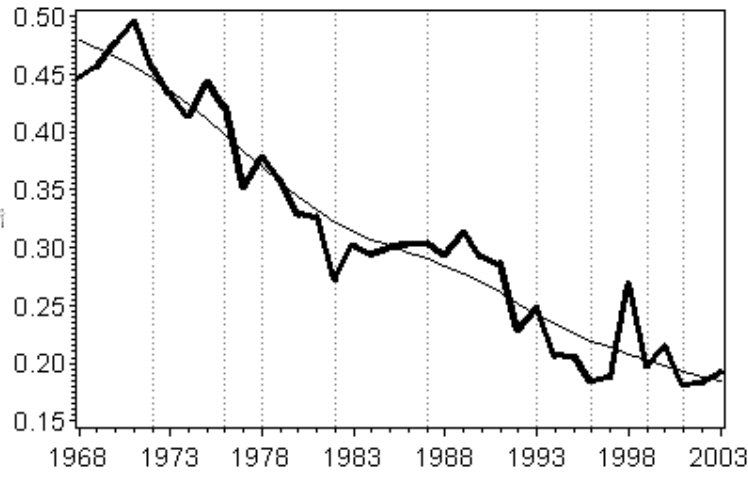

Traffic mortality

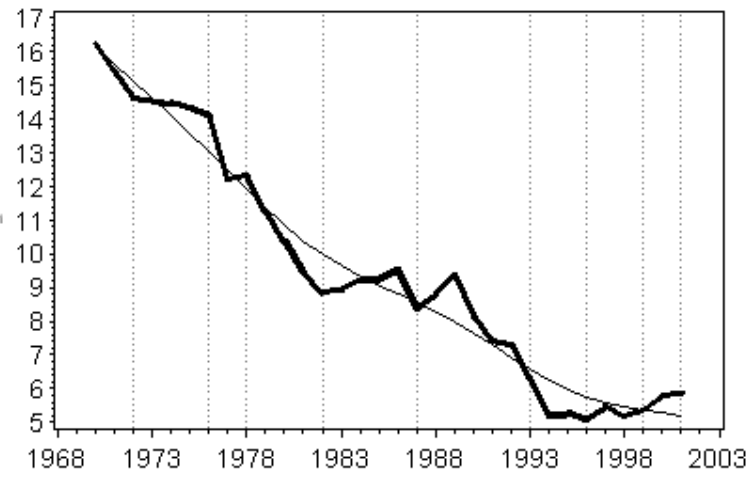


Notes: Real GDP and average hours indexed to 100 for 2000 and 1992, respectively. Mortality is per 100,000; traffic mortality is an age-standardized rate. Vertical dotted lines are business-cycle troughs (OECD chronology). 
Figure 2. Potential pathways linking economic fluctuations to mortality. Black solid arrows represent positive effects, gray dashed arrows, negative effects (e.g., a decrease in economic activity reduces money income, this in turn reduce alcohol consumption which increases immunity levels). The three rectangles shaded in gray represent final steps directly leading to an increase in the risk of death. Many potential pathways (e.g., overtime increasing stress and drinking and decreasing sleep time and social support; stress increasing smoking) have been omitted for clarity

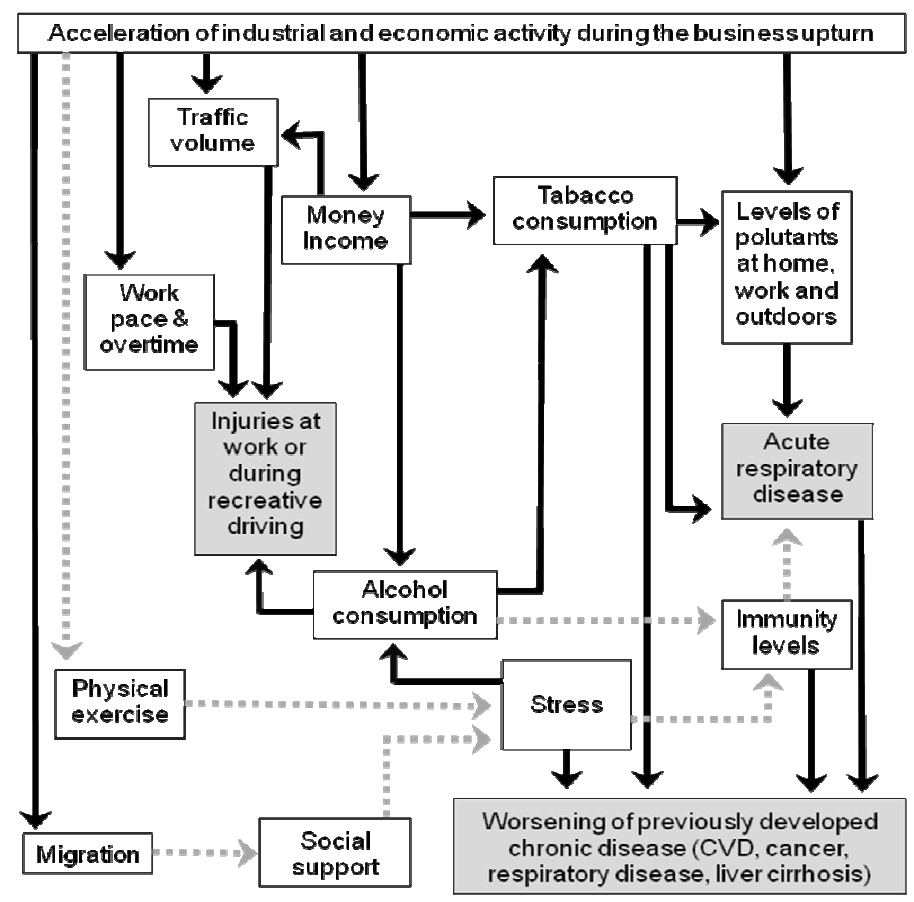


Figure 3. Unemployment rate, inverted (thick gray line in the four panels) and four ageor cause-specific mortality rates. All series are annual data detrended with the HodrickPrescott filter $(\gamma=100)$ and normalized

\section{Mortality ages $10-19$}

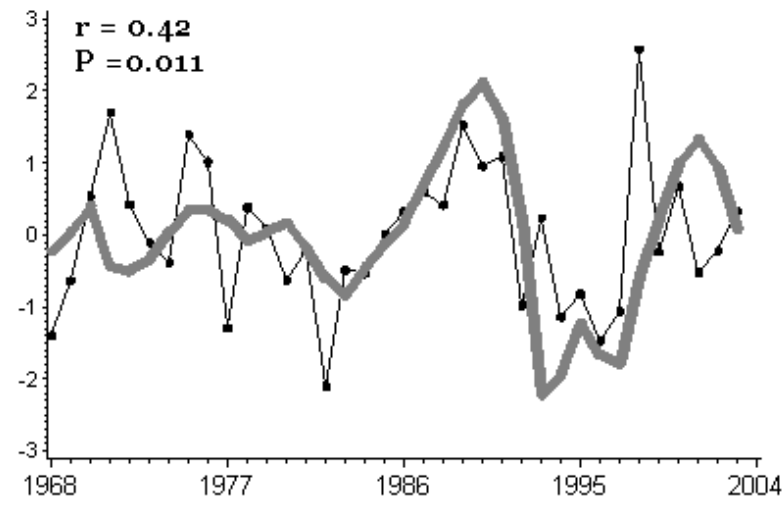

Mortality ages 20-44 females

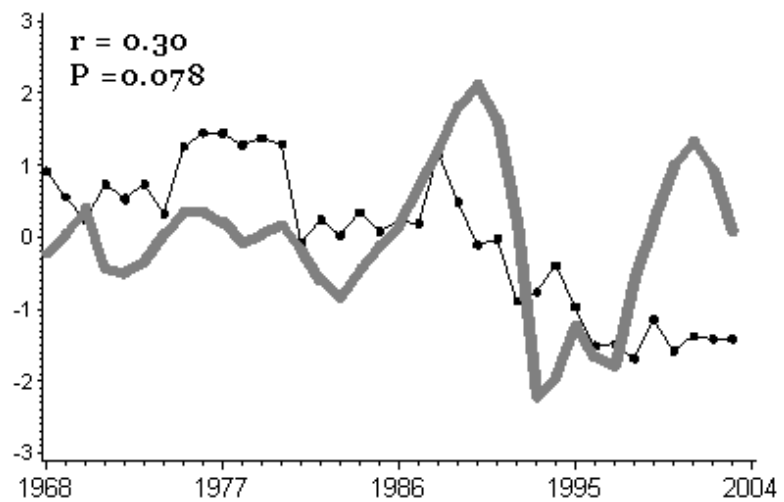

Mortality ages 20-44 males

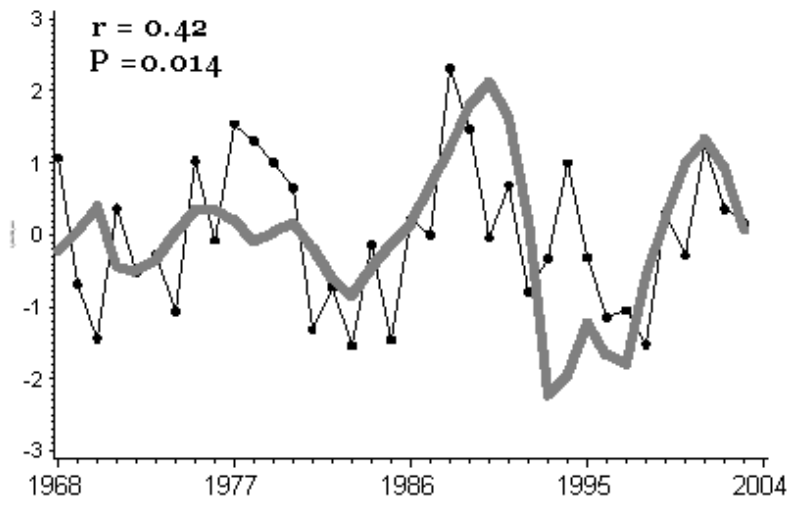

Age-standardized traffic mortality

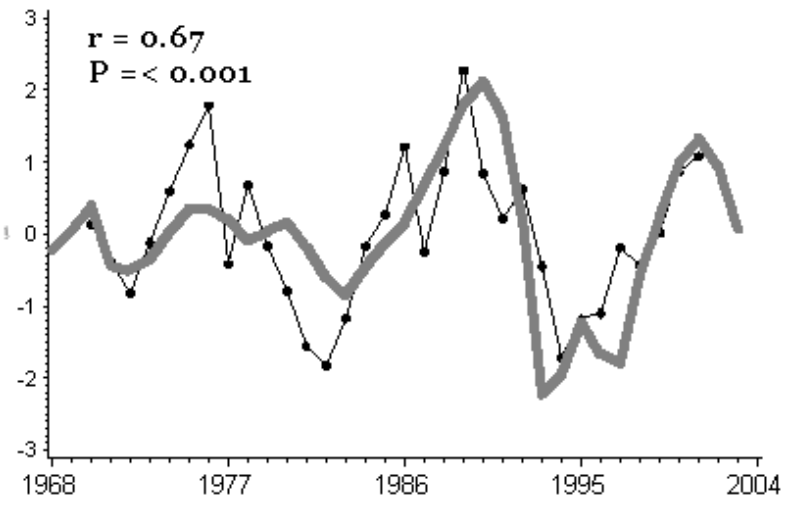




\section{APPENDICES}

\section{APPENDIX A- HP-FILTERING PARAMETER TO BE USED WITH ANNUAL DATA}

A controversy exists among macroeconomists and econometricians about what is the most appropriate value for the smoothing parameter $\gamma$ to compute a trend with the HP filter when annual data are used. Of course, there is no single "correct" value of $\gamma$, the same there is not correct value for the window size when using a moving average. Some theoretical arguments have favored values closer to $\gamma=6.25$, whereas $\gamma=100$ is perhaps the closest to a consensus among practitioners. We will show some empirical results that show $\gamma=100$ is more appropriate for our annual data. Then we will show that using the lowest $\gamma$ value proposed, 6.25, we obtain results that are consistent with the $\gamma=100$ results if properly interpreted.

Accusations of cherrypicking a choice of $\gamma$ could be defused by using a consensus value, but there is no clear consensus. This lack of consensus is presented by Maravall and Del Rio (2007) in these terms (note that they use $\lambda$ as symbol for the smoothing parameter in place of $\gamma$ ):

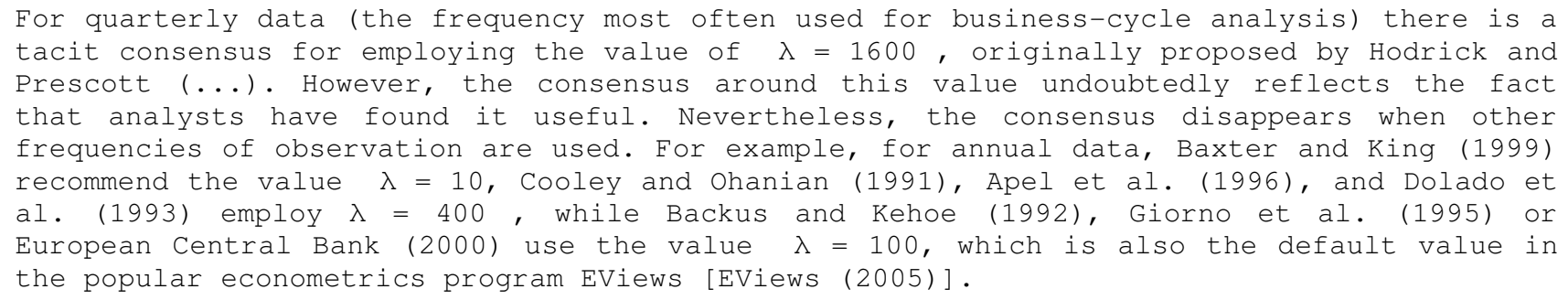

We have noticed that even larger values, such as $\gamma=1000$, have been considered relevant for macroeconomic analyses (Mohun et al., 2008).

We believe, however, that the commonly used $\gamma=100$ is appropriate for our data and investigation, producing "a better detrending”. Let's suppose that a good choice of $\gamma$ should lead to consistency between different indicators of the so-called business cycle. Correlations between HPdetrended business cycle indicators are higher when the detrending is done with $\gamma=100$ than when done with $\gamma=6.25$. For instance, for Swedish data for the years 1968-2003, detrended GDP correlates with unemployment -0.51 and with detrended unemployment -0.85 when $\gamma=100$, but these correlations are respectively -0.34 and -0.81 when $\gamma=6.25$. The same happens with data from the United States, for instance for the years 1950-1999 detrended GDP correlates -0.62 with unemployment and -0.87 with detrended unemployment when detrending the series with $\gamma=100$; the correlations are respectively -0.54 and -0.85 when $\gamma=6.25$. We have also checked crosscorrelations between these and other detrended business cycle indicators (average weekly hours, index of manufacturing production, index of total industrial production); with $\gamma=6.25$ the crosscorrelations are also lower than the cross-correlations between the same indicators detrended with $\gamma=100$. It is our understanding that if business cycles indicators (such as GDP, unemployment, the 
index of industrial production, etc.) are correctly detrended, they will measure equally well the fluctuations of the economy and will correlate at a higher (absolute) value. Contrarily, if they are incorrectly detrended, their correlation may be weak. For instance, the correlation between undetrended GDP and unemployment is almost zero.

Just by inspection of figure 1 and appendix figure A1 one can argue qualitatively that $\gamma=100$ separates better the trend from the variation around the trend in the annual time series analyzed in this paper. Figure A2 provides extra evidence using Swedish historical data. While the trend in the Swedish unemployment rate computed with $\gamma=6.25$ oscillates quite wildly in the 1920s-1930s, so that there are two peaks in that trend line corresponding to the unemployment peaks in 1921 and 1933, the trend computed with $\gamma=100$ reveals a single high unemployment period during the 19201930s. Another example is shown in figure A3, plotting a time series of annual data for life expectancy at birth in Sweden for the years 1900-1950. In this period demographers agree that the trend in life expectancy was constantly increasing. The original series reveals however a deep trough in 1918 caused by the world flu pandemics. Now, that pandemic was only a one-year event, and a procedure that supposedly reveals the trend in the long run should be insensitive to a one-year deviation. That is the case with the HP trend computed with $\gamma=100$. However, the trend computed with $\gamma=6.5$ is strongly affected by the 1918 drop in life expectancy and shows a declining trend of life expectancy several years from the mid-1910s to the end of that decade. Given that we are interested in annual variations, a detrending method that captures these annual variations (so that almost none are detected after detrending) does not seem appropriate.

Finally, tables A1 and A2 show that the results of the paper are not very sensitive to the choice of $\gamma$. In both cases, statistical significance is slightly higher using $\gamma=100$ rather than $\gamma=6.25$. Further, in table 1 it is necessary to include a lag to GDP and unemployment for $\gamma=6.25$ in order to recover the consistency with $\gamma=100$. We believe this is a consequence of the fact that $\gamma=100$ leads to greater statistical power than $\gamma=6.25$. This is an important issue overlooked by the theory of Ravn and Uhlig (2002), which may contribute to explain why practitioners have been slow to adopt their recommendation of $\gamma=6.25$. To understand this fact, we consider the frequencies removed by detrending with these different choices of $\gamma$.

Let us say that $\gamma=100$ removes low frequencies and $\gamma=6.25$ removes both low and moderate frequencies. In the time domain, this means that the trend line for $\gamma=6.25$ follows the data more closely (see figure 1, and appendix figures A1, and A2). Examining only high frequencies is a more rigorous test of a high frequency effect, but distributed-lag relationships have their statistical information spread across all frequencies. As long as the desired relationship holds at medium frequencies, one can expect to get greater statistical power by not filtering these frequencies out. Having established that our results are not driven disproportionately by these medium frequencies, it makes the strongest case for our conclusions to include these frequencies in our primary analysis. 
Whereas table A2 shows almost complete consistency between $\gamma=6.25$ and $\gamma=100$, table A1 has an interesting wrinkle. To match the results with $\gamma=100$, it is necessary to include a lag for unemployment and GDP, but not for average hours in manufacturing. The explanation for this is that the distributed lag relationship is primarily at lag one for GDP and unemployment, but it is at lag zero for average hours in manufacturing. The simple unlagged correlations in table A1 are presented as an immediately accessible analysis with neither the complexity nor the additional modeling assumptions of our subsequent analysis. However, the consistent lag-zero effect of a lagone relationship shows up only in medium to low frequency components which are filtered out by $\gamma$ $=6.25$. Thus, the analysis restricted to $\gamma=6.25$ forces us to use the "correct" lag in table A1. Though this might be considered desirable, it can be considered overall as a disadvantage. While the paper has plenty of technical discussion of lags, and tables 5, 6, and 7 provide results of lag regression models, table 1 is impressive primarily because of the remarkably consistent pattern of signs across various measures of health and economic indicators.

\section{APPENDIX B - ADJUSTMENTS FOR AUTOCORRELATION}

The results of lag regression models that are presented in the paper do not present $P$ values adjusted by using robust standard errors. Robust standard errors are known to be substantially more variable, and typically give rise to anti-conservative $P$ values (Kauermann and Carroll, 2001). This mandates using robust standard errors only when there is a clear reason to do so. In addition, different robustifications lead to slightly different results, requiring robustness analysis on the specification of the robust standard errors. At any rate, to show the robustness of our results to the use of robust standard errors, we present some results in table B1. As we anticipated in footnote 7 , using robust standard errors the estimated statistical significance is generally slightly higher than for unmodified standard errors.

Table B1 reports Newey-West robust standard errors for the models whose results were presented in table 5. A robustness analysis showed that these robust standard errors are themselves robust to the choice of the bandwidth parameter (results not shown). We carried out our robustness analysis on this table because it concerns the situation where standard Newey-West robust standard errors are most immediately applicable. Table B1 indicates that, as proposed in footnote 7 , our unadjusted standard errors are slightly conservative. By contrast, many investigators have reported that Newey-West type standard errors are typically anti-conservative (Kauermann and Carroll, 2001, and references therein). Thus we view with caution the additional statistical significance claimed by these methods. In situations with positively autocorrelated errors, Newey-West type standard errors may be less over-optimistic than unadjusted errors. Here we are, however, in the opposite situation with generally negatively autocorrelated errors. To convince a skeptic about the validity of our results, the unadjusted standard errors therefore make a stronger argument. 
However, presenting adjusted standard errors as additional results makes the argument even more secure.

Table A1. Cross-correlations between three economic indicators, life expectancy, and selected mortality rates for Sweden, 1968-2003

\begin{tabular}{|c|c|c|c|c|c|c|c|c|}
\hline \multirow[b]{3}{*}{$\underline{\text { Health indicator }}$} & \multicolumn{3}{|c|}{$\begin{array}{l}\text { All variables detrended with the } \\
\text { Hodrick-Prescott filter, } \gamma=100\end{array}$} & \multicolumn{5}{|c|}{$\begin{array}{l}\text { All variables detrended with the } \\
\text { Hodrick-Prescott filter, } \gamma=6.25\end{array}$} \\
\hline & Lag 0 & Lag 0 & Lag 0 & Lag 0 & Lag 0 & Lag 0 & Lag 1 & $\operatorname{Lag} 1$ \\
\hline & $\begin{array}{c}\text { Unem- } \\
\text { ployment }\end{array}$ & GDP & $\begin{array}{l}\text { Avrg. hrs. in } \\
\text { manuf. }\end{array}$ & $\begin{array}{c}\text { Unem- } \\
\text { ployment }\end{array}$ & GDP & $\begin{array}{l}\text { Avrg. hrs. in } \\
\text { manuf. }\end{array}$ & $\begin{array}{c}\text { Unem- } \\
\text { ployment }\end{array}$ & GDP \\
\hline Life expectancy & $0.34^{\dagger}$ & -0.15 & $0.53^{* *}$ & 0.03 & 0.11 & $0.39^{*}$ & 0.23 & -0.23 \\
\hline LE, males & $0.38^{*}$ & -0.19 & $0.51^{* *}$ & 0.01 & 0.14 & $0.33^{\dagger}$ & 0.18 & -0.16 \\
\hline LE, females & 0.28 & -0.10 & $0.51^{* *}$ & 0.05 & 0.07 & $0.41^{*}$ & 0.26 & -0.26 \\
\hline ASMR, all ages & -0.27 & 0.21 & $-0.40^{*}$ & 0.02 & -0.02 & $-0.32^{\dagger}$ & -0.29 & $0.32^{\dagger}$ \\
\hline ASMR, males & -0.19 & 0.12 & $-0.37^{*}$ & 0.05 & -0.08 & $-0.30^{\dagger}$ & -0.27 & 0.29 \\
\hline ASMR, females & $-0.31^{\dagger}$ & 0.26 & $-0.38^{*}$ & -0.02 & 0.04 & $-0.32^{\dagger}$ & $-0.30^{\dagger}$ & $0.34^{\dagger}$ \\
\hline $\begin{array}{l}\text { Crude mortality } \\
\text { rate }\end{array}$ & -0.24 & 0.11 & $-0.39^{*}$ & 0.05 & -0.12 & $-0.38^{*}$ & -0.27 & 0.26 \\
\hline CMR, males & -0.17 & 0.08 & $-0.37^{*}$ & 0.11 & -0.17 & $-0.37^{*}$ & -0.20 & 0.20 \\
\hline CMR, females & -0.27 & 0.14 & $-0.38^{*}$ & 0.01 & -0.07 & $-0.36^{*}$ & $-0.31^{\dagger}$ & $0.29^{\dagger}$ \\
\hline Infant mortality & $-0.41^{*}$ & 0.24 & -0.16 & -0.05 & -0.18 & -0.07 & -0.24 & 0.21 \\
\hline $0-4$ & $-0.48^{* *}$ & $0.36^{*}$ & $-0.34^{*}$ & -0.11 & -0.03 & -0.16 & -0.26 & $0.33^{\dagger}$ \\
\hline $5^{-9}$ & -0.01 & -0.08 & $-0.34^{*}$ & 0.10 & -0.08 & $-0.36^{*}$ & 0.05 & -0.22 \\
\hline $10-19$ & $-0.42^{* *}$ & $0.52^{* *}$ & -0.12 & -0.12 & 0.18 & -0.10 & 0.00 & 0.05 \\
\hline $20-44$ & $-0.42^{* *}$ & $0.36^{*}$ & -0.21 & -0.05 & 0.18 & 0.22 & 0.19 & -0.12 \\
\hline $25-64$ & $-0.30^{\dagger}$ & 0.17 & $-0.34^{*}$ & -0.19 & 0.17 & -0.01 & -0.05 & 0.19 \\
\hline $45^{-64}$ & -0.25 & 0.11 & $-0.33^{*}$ & -0.19 & 0.12 & -0.11 & -0.18 & $0.30^{\dagger}$ \\
\hline $55^{-64}$ & -0.26 & 0.07 & $-0.42^{* *}$ & -0.20 & 0.10 & -0.18 & -0.17 & 0.24 \\
\hline $65-84$ & -0.03 & -0.13 & $-0.37^{*}$ & 0.11 & -0.18 & $-0.36^{*}$ & -0.18 & $0.30^{\dagger}$ \\
\hline
\end{tabular}

Notes: Correlations with mortality rates are based on $n=36$ or close to 36 in most cases; in life expectancy correlations, $n=30$. ASMR is age-standardized mortality rate.

$+P<0.1 * P<0.05{ }^{* *} P<0.01 \quad+P<0.1$. 
Table A2. Effects of the regional unemployment rate on regional mortality in lag regression models. For each dependent variable (mortality rate) the lag specification selected is that minimizing AIC out of the four possible lag lengths. Series detrended with the Hodrick-Prescott filter using $\gamma=6.25$. Compare with table 7, panel B, where $\gamma=100$ was used

\begin{tabular}{lcccc}
\hline & Lag O & Lag 1 & Lag 2 & Lag 3 \\
\hline Total mortality & 0.95 & $-4.70^{*}$ & & \\
Male mortality & $4.51^{\dagger}$ & $-8.28^{* *}$ & & \\
Female mortality & -1.66 & & \\
$\quad$ Age- or cause-specific mortality & & & \\
Ages 20-44 & -0.46 & & \\
Ages 45-64 & 0.55 & $-3.98^{\dagger}$ & \\
Ages 65+ & 5.25 & $-23.88^{*}$ & \\
Ischemic heart disease & 2.41 & -2.93 & $4.14^{*}$ & \\
Traffic injuries & -0.07 & & & \\
\hline
\end{tabular}

Notes: $\dagger P<0.1 \quad * P<0.05 \quad * * P<0.01$.

Data for the years 1980-2005, in 21 Swedish regions. Models include a random effect for each year, to adjust for the spatial autocorrelation of the regional mortality rates. Observations are weighted by the square root of the regional population to adjust for heteroskedasticity. 
Table B1. Models with a health indicator in first differences regressed on a constant, and coincidental and lagged values-except in panel $\mathrm{C}$ - of an economic indicator. OLS standard errors (SE) below the parameter estimate, followed (in square brackets) by Newey-West heteroskedasticity and autocorrelation-consistent SE (bandwidth = 2). Marks showing statistical significance next to the parameter estimates correspond to the unadjusted SE (as in table 5). The marks next to the robust SE show the statistical significance of the corresponding parameter estimates according to the Newey-West methodology

\begin{tabular}{|c|c|c|c|c|c|c|c|c|}
\hline $\begin{array}{l}\text { Explanatory } \\
\text { variable }\end{array}$ & $\begin{array}{l}\text { Dependent } \\
\text { variable }\end{array}$ & Lag 0 & Lag 1 & $n$ & $d$ & $R^{2}$ & Model & Interpretation of the net effect \\
\hline \multirow{6}{*}{ 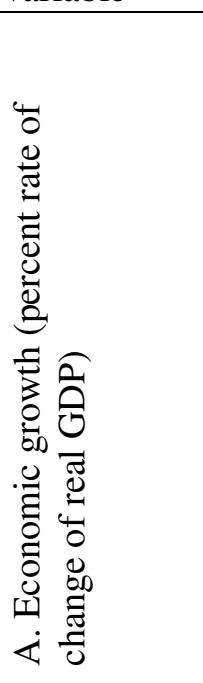 } & $\begin{array}{l}\text { Life expec- } \\
\text { tancy }\end{array}$ & $\begin{array}{l}0.027 \\
(0.019)\end{array}$ & $\begin{array}{l}\mathbf{0 . 0 4 1} * \\
(0.019)\end{array}$ & 31 & $2.70^{\mathrm{a}}$ & 0.15 & [1] & Procyclical mortality \\
\hline & & {$[0.023]$} & {$[0.017]^{*}$} & & & & & \\
\hline & $\begin{array}{l}\text { Crude mor- } \\
\text { tality }\end{array}$ & $\begin{array}{l}-0.039 \\
(0.023) \\
{[0.031]}\end{array}$ & $\begin{array}{l}\mathbf{0 . 0 4 8}^{*} \\
(0.023) \\
{[0.026] \dagger}\end{array}$ & 32 & 2.74 & 0.14 & [2] & Procyclical mortality \\
\hline & $\begin{array}{l}\text { Mortality } \\
\text { ages } 20-44\end{array}$ & $\begin{array}{l}0.003 \\
(0.003) \\
{[0.003]}\end{array}$ & $\begin{array}{l}0.000 \\
(0.003) \\
{[0.003]}\end{array}$ & 35 & 2.46 & 0.02 & [3] & \\
\hline & $\begin{array}{l}\text { Mortality } \\
\text { ages 45-64 }\end{array}$ & $\begin{array}{l}0.003 \\
(0.012) \\
{[0.011]}\end{array}$ & $\begin{array}{l}0.022 \dagger \\
(0.012) \\
{[0.007]^{* *}}\end{array}$ & 35 & 1.76 & 0.12 & [4] & Procyclical mortality \\
\hline & $\begin{array}{l}\text { Mortality } \\
\text { ages } 65-84\end{array}$ & $\begin{array}{l}-\mathbf{0 . 1 7 3 \dagger} \\
(0.085) \\
{[0.130]}\end{array}$ & $\begin{array}{l}0.124 \\
(0.085) \\
{[0.083]}\end{array}$ & 35 & 2.89 & 0.13 & [5] & $\begin{array}{l}\text { Countercyclical mortality } \\
\text { [No effect] }\end{array}$ \\
\hline \multirow{5}{*}{ 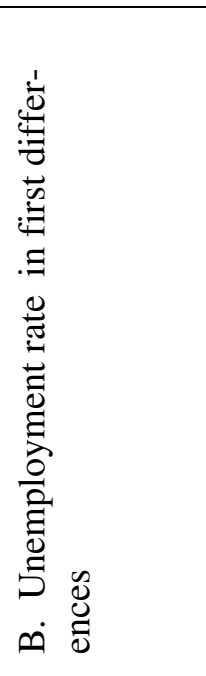 } & $\begin{array}{l}\text { Life expec- } \\
\text { tancy }\end{array}$ & $\begin{array}{c}-0.026 \\
(0.042) \\
{[0.041]}\end{array}$ & $\begin{array}{l}\mathbf{0 . 0 7 6 \dagger} \\
(0.043) \\
{[0.033]^{*}}\end{array}$ & 30 & 2.64 & 0.11 & [6] & Procyclical mortality \\
\hline & $\begin{array}{l}\text { Crude mor- } \\
\text { tality }\end{array}$ & $\begin{array}{c}0.076 \\
(0.050) \\
{[0.043] \dagger}\end{array}$ & $\begin{array}{l}-\mathbf{0 . 1 1 9} * \\
(0.050) \\
{[0.039]^{* *}}\end{array}$ & 34 & 2.45 & 0.15 & [7] & Procyclical mortality \\
\hline & $\begin{array}{l}\text { Mortality } \\
\text { ages 20-44 }\end{array}$ & $\begin{array}{c}-0.006 \\
(0.007) \\
{[0.005]}\end{array}$ & $\begin{array}{l}0.002 \\
(0.007) \\
{[0.005]}\end{array}$ & 34 & 2.55 & 0.02 & {$[8]$} & \\
\hline & $\begin{array}{l}\text { Mortality } \\
\text { ages 45-64 }\end{array}$ & $\begin{array}{c}-0.018 \\
(0.025) \\
{[0.016]}\end{array}$ & $\begin{array}{l}-0.018 \\
(0.025) \\
{[0.012]}\end{array}$ & 34 & 1.62 & 0.07 & [9] & \\
\hline & $\begin{array}{l}\text { Mortality } \\
\text { ages 65-84 }\end{array}$ & $\begin{array}{r}\mathbf{0 . 3 2 7 \dagger} \\
(0.186) \\
{[0.136]^{*}} \\
\end{array}$ & $\begin{array}{l}-\mathbf{0 . 3 7 9} \dagger \\
(0.187) \\
{[0.104]^{* *}}\end{array}$ & 34 & 2.45 & 0.13 & [10] & Equivocal \\
\hline \multirow{5}{*}{ 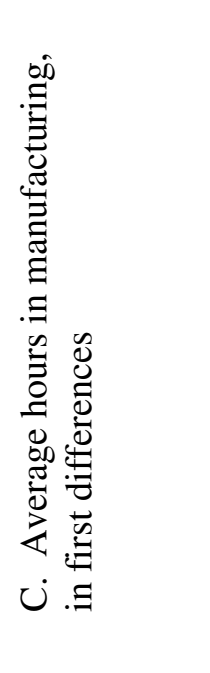 } & $\begin{array}{l}\text { Life expec- } \\
\text { tancy }\end{array}$ & $\begin{array}{c}\mathbf{0 . 0 4 3 \dagger} \\
(0.023) \\
{[0.015]^{* *}}\end{array}$ & & 31 & $2.96^{\mathrm{a}}$ & 0.11 & [11] & Procyclical mortality \\
\hline & $\begin{array}{l}\text { Crude mor- } \\
\text { tality }\end{array}$ & $\begin{array}{r}-\mathbf{0 . 0 5 9} * \\
(0.027) \\
{[0.022]^{*}}\end{array}$ & & 35 & $2.93^{\mathrm{a}}$ & 0.12 & [12] & Procyclical mortality \\
\hline & $\begin{array}{l}\text { Mortality } \\
\text { ages 20-44 }\end{array}$ & $\begin{array}{c}-0.002 \\
(0.004) \\
{[0.003]}\end{array}$ & & 33 & 2.43 & 0.01 & [13] & \\
\hline & $\begin{array}{l}\text { Mortality } \\
\text { ages 45-64 }\end{array}$ & $\begin{array}{c}-\mathbf{0 . 0 3 3} * \\
(0.014) \\
{[0.011]^{* *}}\end{array}$ & & 35 & 2.11 & 0.14 & {$[14]$} & Procyclical mortality \\
\hline & $\begin{array}{l}\text { Mortality } \\
\text { ages } 65-84\end{array}$ & $\begin{array}{c}-0.014 \\
(0.105) \\
{[0.079] \dagger}\end{array}$ & & 35 & $2.96^{\mathrm{a}}$ & 0.05 & [15] & [Procyclical mortality] \\
\hline
\end{tabular}


$\dagger P<0.1 \quad * P<0.05 \quad$ a $P<0.05$. Data include years from 1968 to the early 2000 . Estimates statistically significant at a confidence level of $90 \%$ or higher are highlighted in boldface. Mortality rates are measured in deaths per 1,00o population, life expectancy in years. The interpretation of the net effect (last column to the right) is identical when the standard errors are OLS computed and when they are computed with the Newey-West method, except in two cases, in which a new interpretation has been added in square brackets and italics. 
Figure A1. Selected variables used in the study. The thin curves are Hodrick-Prescott trends computed with a smoothing parameter $\gamma=6.25$. Compare with figure 1 in which $\gamma=100$

Real GDP

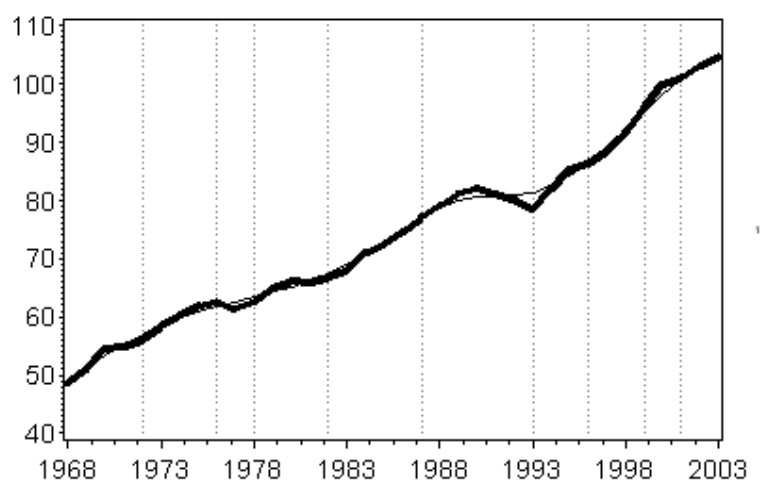

Average hours in manufacturing

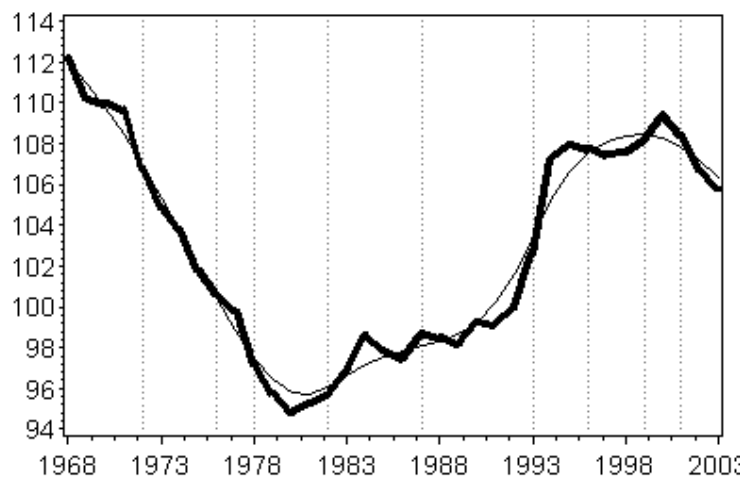

Age-adj. mortality

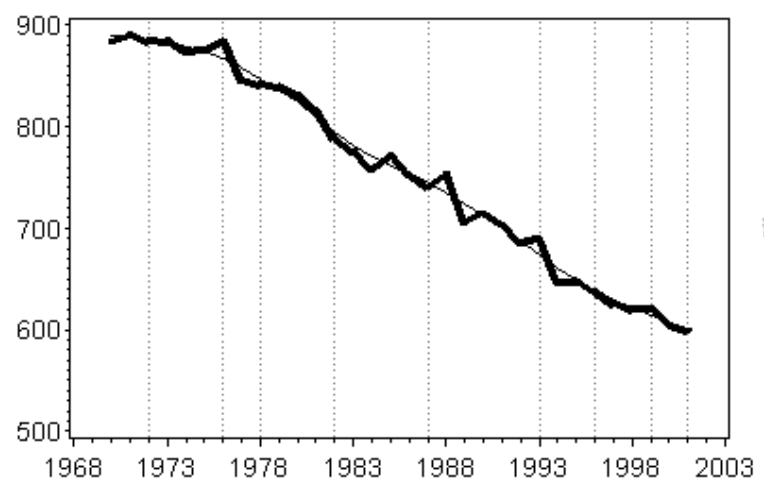

Mortality ages 20-44

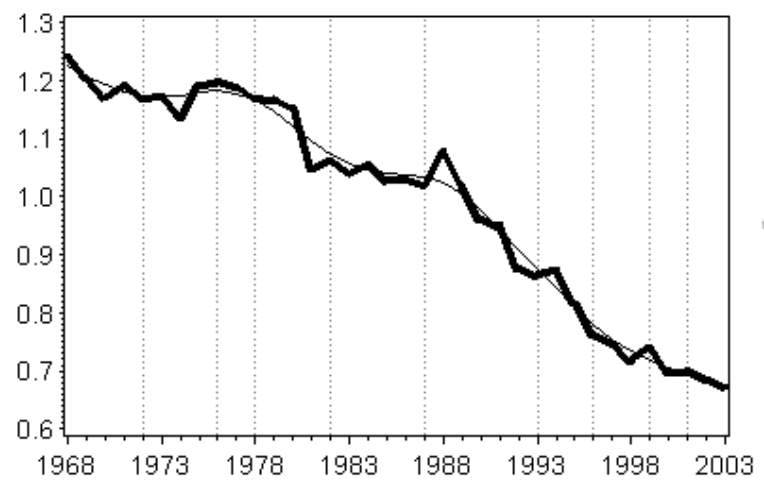

Unemployment rate $(\%)$

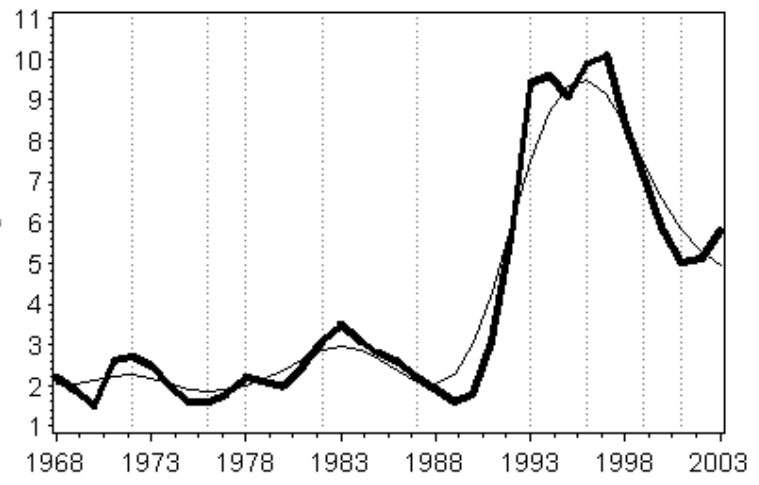

Life expectancy at birth

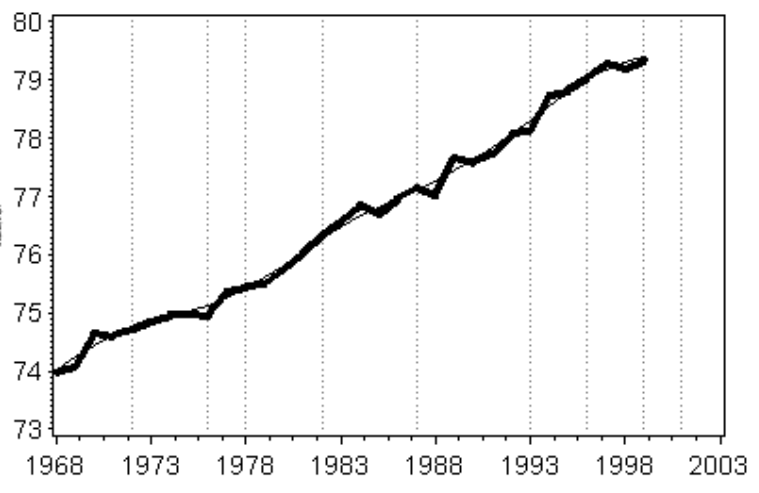

Mortality ages 10-19

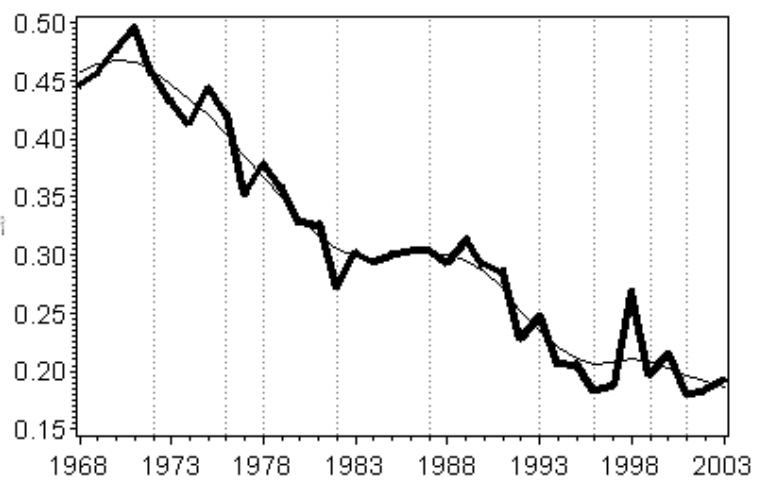

Traffic mortality

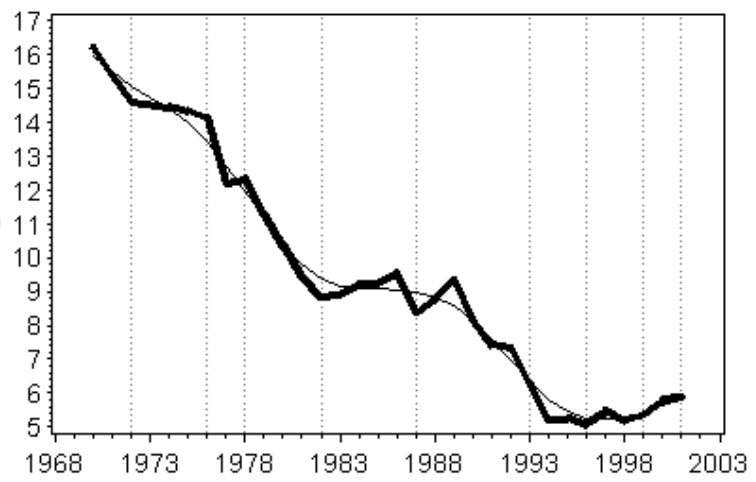


Figure A2. Unemployment in Sweden, 1910-2000. The thick solid line is the annual unemployment rate. The other two lines are trends estimated with the HP filter, using a smoothing parameter $\gamma=6.25$ (thin solid line) or $\gamma=100$ (dashed line)

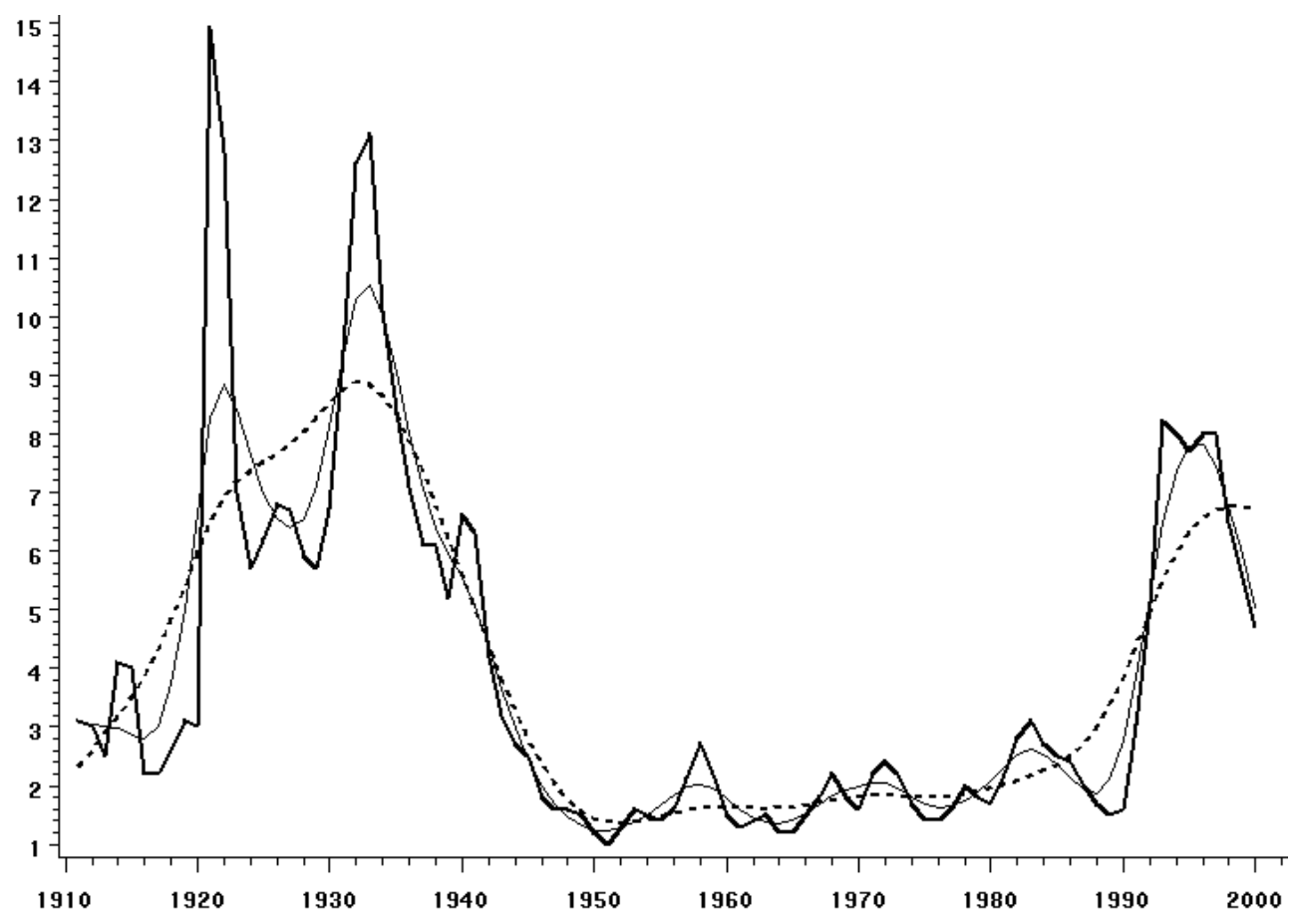

Figure A3. Life expectancy in Sweden, 1900-1950

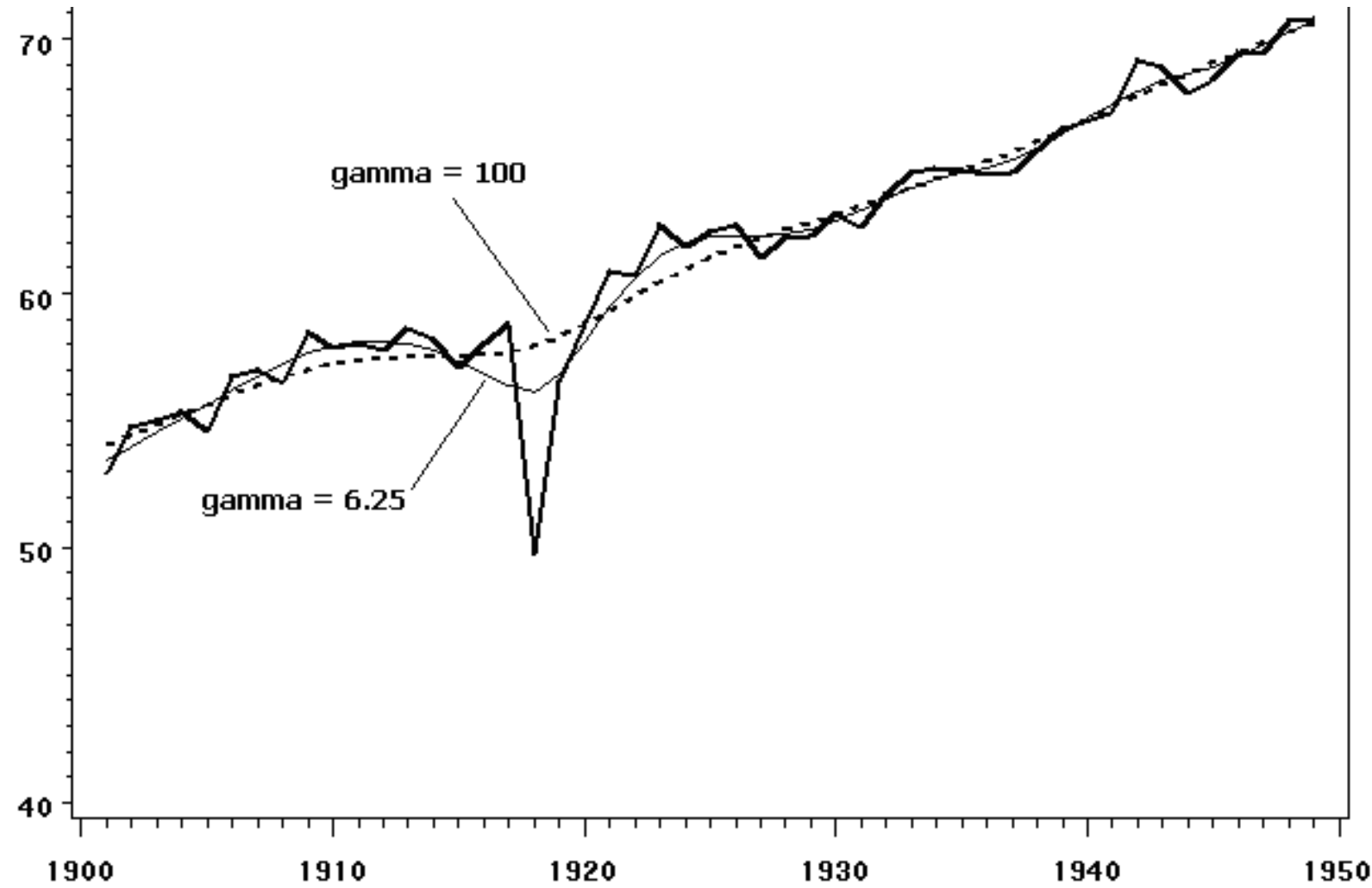




\section{REFERENCES}

Abdala, F., Geldstein, R. N. \& Mychaszula, S. M. (2000). Economic restructuring and mortality changes in Argentina - Is there any connection? In Cornia, G. A. \& Paniccià, R., eds. The mortality crisis in transitional economies (pp. 328-350). New York: Oxford University Press.

Ashley, R, \& Verbrugge, R.J. (2006). Coments on "A critical investigation on detrending procedures for non-linear processes". Journal of Macroeconomics 28, 192-194.

Backus, D. K. \& Kehoe, O. J. (1992). International evidence on the historical properties of business cycles. American Economic Review 82, 864-888.

Baker, S., O’Neill, B. \& Karpf, R. (1984). The injury fact book. Lexington, MA: Lexington Books.

Baxter, M., \& King, R.G. (1999). Measuring business cycles: approximate band-pass filters for economic time series. Review of Economics \& Statistics, 81(4), 575-593.

Bengtsson, T, \& Saito, O., eds. (2000). Population \& Economy: From Hunger to Modern Economic Growth. Oxford: Oxford University Press.

Bengtsson, T., Campbell, C., Lee, J. Z. et al. (2004). Life under Pressure-Mortality and Living Standards in Europe and Asia, 1700-190o. Cambridge, MA: The MIT Press.

Biddle, J. E. \& Hamermesh, D. S. (1990). Sleep and the allocation of time. Journal of Political Economy 98, 922-943.

Brenner, M. H. (1971). Economic changes and heart disease mortality. American Journal of Public Health, 61(3), 606-611.

Brenner, M. H. (1979). Mortality and the national economy: A review, and the experience of England and Wales, 1936-76. Lancet, 2(8142), 568-573.

Brenner, M. H. (1982). Economic change and sex-specific cardiovascular mortality in Britain 1955-1976. Social Science \& Medicine, 16(4), 431-442.

Brenner, M. H. (1987). Relation of economic change to Swedish health and social well-being, 1950-1980. Social Science \& Medicine, 25(2), 183-195.

Brenner, M. H. (1995). Political economy and health. In Amick III, B. C., Levine, S., Tarlov, A.R. \& Walsh, D.C.,eds. Society and health. New York: Oxford University Press.

Buchmueller, T., Grignon, M., \& Just, F. (2007). Unemployment and mortality in France, 1982-2002. CHEPA Working Paper 07-04, Dept. of Economics, McMaster University, Toronto.

Bunn, A.R. 1979, Ischaemic heart disease mortality and the business cycle in Australia, American Journal of Public Health, 69(8), 772-781.

Bunn, A.R. 1980, IHD mortality and the business cycle in Australia. American Journal of Public Health, 70(4), 409-411. 
Chay, K. Y. \& Greenstone, M. (2003). The impact of air pollution on infant mortality: Evidence from geographic variation in pollution shocks induced by a recession. Quarterly Journal of Economics, 118(3), 1121-1167.

Chung H. 2007. Flexibility for employers or for employees? A new approach to examining labour market flexibility across Europe using company level data. In: Jørgensen H, Madsen PK, eds. Flexicurity and beyond: Finding a new agenda for the European social model (pp. 243-277). Copenhagen: DJØF.

Claeskens G. \& Hjort, N. (2008). Model selection and model averaging. Cambridge: Cambridge University Press.

Dagum, E.B. \& Giannerini, S. (2006). A critical investigation on detrending procedures for non-linear processes. Journal of Macroeconomics, 28(1), 175-191.

Daly, H. E. (1977). Steady-state economics-The economics of biophysical equilibrium and moral growth. San Francisco: W. H. Freeman.

Dehejia, R., \& Lleras-Muney, A. (2004). Booms, busts, and babies' health. Quarterly Journal of Economics, 119, 3, 1091-1130.

Diggle, Peter J. (1990). Time series-A biostatistical introduction. Oxford: Clarendon Press.

Edwards, R. D. (2005). Commentary: Work, well-being, and a new calling for countercyclical policy, International Journal of Epidemiology, 34, 1222-1225.

Edwards, R.. (2008). Who is hurt by procyclical mortality? Social Science \& Medicine 67(12), 2051-2058.

Eyer, J. (1976a). Review of Mental-Illness and the Economy. International Journal of Health Services, 6(1), 139-148.

Eyer, J. (1976b). Rejoinder, International Journal of Health Services, 6(1), 157-168.

Eyer, J. (1977). Does unemployment cause a death rate peak in each business cycle? International Journal of Health Services, 7(4), 625-662.

Eyer, J. (1977b). Prosperity as a cause of death. International Journal of Health Services, 7(1), 125-150.

Eyer, J. (1984). Capitalism, health, and illness. In McKinlay, J. B., ed. Issues in the Political Economy of Health Care (pp. 23-59). New York: Tavistock.

Fishback, P. V., Haines, M. R. \& Kantor, S. (2007), Births, deaths, and New Deal relief during the Great Depression. Review of Economics \& Statistics, 84(1), 1-14.

Forbes, J.B. \& McGregor, A. (1984). Unemployment and mortality in post-war Scotland. Journal of Health Economics, 2, 239-257.

Fridlizius, G. (1979). Sweden. In Lee, W. R., ed. European Demography and Economic Growth. London: Croom-Helm.

Galbraith, V. L. \& Thomas, D. S. (1941). Birth rates and the interwar business cycles. Journal of the American Statistical Association, 36(216), 465-475. 
Galloway, P.R. (1988). Basic patterns in annual variations in fertility, nuptiality, mortality, and prices in pre-industrial Europe. Population Studies, 42(2), 275-302.

Gerdtham, U.-G. \& Johannesson, M. (2005). Business cycles and mortality: Results from Swedish microdata. Social Science \& Medicine, 60(1), 205-218.

Gerdtham, U.-G. \& Ruhm, C. (2006). Deaths rise in good economic times: Evidence from the OECD. Economics \& Human Biology, 4(4), 298-316.

Georgescu-Roegen, Nicholas (1966). Analytical economics: Issues and problems. Cambridge: Harvard University Press.

Georgescu-Roegen, N. (1971). The entropy law and the economic process. Cambridge: Harvard University Press.

Glass, G.V., Willson, V. L. \& Gottman, J. (1975). Design and analysis of time-series experiments. Boulder: Colorado Associated University Press.

González, F., Quast, T. (2010). Macroeconomic changes and mortality in Mexico. Empirical Economics, March. DOI:10.1007/s00181-010-0360-0

Graham, J.D., Chang, B., \& Evans, J. (1992). Poorer is riskier. Risk Analysis, 12, 333-337.

Gravelle, H. S., Hutchinson, G. \& Stern, J (1981), Mortality and unemployment: A critique of Brenner's time-series analysis. Lancet, 2(8248), 675-679.

Higgs, R. (1979). Cycles and trends of mortality in 18 large American cities, 1871-1900. Explorations in Economic History, 16, 381-408.

Hirsch, F. (1976). Social limits to growth. Cambridge: Harvard University Press.

Isaacs, S, \& Schroeder, S. A. (2005). Class-The ignored determinant of the nation's health. New England Journal of Medicine 351(11), 1137-1142.

Johansson, E. (2004). A note on the impact of hours worked on mortality in the OECD. European Journal of Health Economics, 4, 335-340.

Junankar, P.N. (1991). Unemployment and mortality in England and Wales: a preliminary analysis. Oxford Economic Papers, 43, 305-320.

Kasl, S. (1979). Mortality and the business cycle: some questions about research strategies when utilizing macro-social and ecological data. American Journal of Public Health, 69(8), 784-789.

Kauermann, G., Carroll, R.J. (2001). A note on the efficiency of sandwich covariance. JASA 96:1387-1496 (http://www.jstor.org/stable/3085907).

Khang, Y..H., Lynch, J., \& Kaplan-Oso, G. (2005). Impact of economic crisis on mortality in South Korea. International Journal of Epidemiology, 34(6), 1291-1301.

Laporte, A. (2004). Do economic cycles have a permanent effect on population health? Revising the Brenner hypothesis. Health Economics, 13, 767-779.

Layne, L. J. (2007). Appendix 4: Spatial autocorrelation. In Stephen J. Kunitz, The Health of Populations. New York: Oxford University Press. 
Lee, R. (1981). Short-term variation-Vital rates, prices, and weather. In Wrigley, E. A. \& Schofield, R. S. The population history of England 1541-1971--A reconstruction (pp. 356401). London: Edward Arnold.

Lew, A. (1979). Mortality and the business cycle: how far can we push an association? American Journal of Public Health, 69, 782-783.

Liu, Y, Tanaka, H., \& Fukuoka Heart Study Group (2002). Overtime work, insufficient sleep, and risk of non-fatal acute myocardial infarction in Japanese men. Occupational \& Environmental Medicine, 59:7, 447-451.

Livi-Bacci, M. (1991). Population and nutrition-An essay on European demographic history.New York: Cambridge University Press.

Maravall, A. \& del Río, A. (2007). Temporal aggregation, systematic sampling, and the Hodrick-Prescott filter. Computational Statistics \& Data Analysis 52(2):975-998.

McAvinchey, I.D. (1984). Economic factors and mortality: some aspects of the Scottish case 1950-1978. Scottish Journal of Political Economy, 31(1), 1-27.

McKee, Martin \& M. Suhrcke. (2005). Commentary: Health and economic transition. International Journal of Epidemiology, 34, 1203-1206.

McKinlay, J. B., McKinlay, S, M., \& Beaglehole, R. (1989). Trends in death and disease and the contribution of medical measures. In Freeman, H. E. \& Levine, S., eds. Handbook of medical sociology, 2nd ed. (pp. 14-45). Englewood Cliffs, NJ: Prentice Hall.

Mishan, E. J. (1970). Technology and growth-The price we pay. New York, Praeger.

Mitchell, W. C. (1951). What happens during business cycles-A progress report. New York: National Bureau of Economic Research.

Mohun, S., \& Veneziani, R. (2008). Goodwin cycles and the US economy, 1948-2004. In: Flaschel P, Landesmann M, eds. Mathematical economics and the dynamics of capitalism: Godwin's legacy continued (pp. 107-130). New York: Routledge.

Neumayer, E. (2004). Recessions lower (some) mortality rates-Evidence from Germany. Social Science \& Medicine, 58(6), 1037-1047 [corrigendum in Social Science \& Medicine 59(9].

OECD, OECD Composite Leading Indicators: Reference Turning Points. Accessed in 2006 in http://www.oecd. org/document/41/o,2340,en_2649_34349_1891177_1_1_1_1,oo.html.

Ogburn, W. F. (1964). The fluctuations of business as social forces [1923]. In Duncan, O. D. ed. William F. Ogburn on culture and social change (pp. 235-246). Chicago: University of Chicago Press.

Ogburn, W. F. \& Thomas, D. S. (1922). The influence of the business cycle on certain social conditions. Journal of the American Statistical Association, 18, 324-340. 
Organisation for Economic Co-operation and Development, 2006.

http://www.oecd.org/document/41/o,2340,en_2825_495677_1891177_1_1_1_1,oo.html (consulted in September 2006).

Randolph Beard, T., \& Lozada, G.. (1999). Economics, entropy and the environment-The extraordinary economics of Nicholas Georgesçu-Roegen. Northampton, MA: Edward Elgar.

Ravn, M.O. \& Uhlig, H. (2002). On adjusting the Hodrick-Prescott filter for the frequency of observations. Review of Economics \& Statistics, 84(2), 371-380.

Ruhm, C.J. (2000). Are recessions good for your health? Quarterly Journal of Economics, 115(2), 617-650.

Ruhm, C. J. (2004). Macroeconomic conditions, health, and mortality. Cambridge: MA: National Bureau of Economic Research, NBER Working Paper 11007,

Ruhm, C. J. (2005a). Commentary: Mortality increases during economic upturns. International Journal of Epidemiology, 34, 1206-1211.

Ruhm, C. J. (2005b). Macroeconomic conditions and deaths from coronary heart disease, NBER and University of North Carolina, Greensboro, NC.

Ruhm, C. J. (2005c). Healthy living in hard times. Journal of Health Economics 24, 341363.

Ruhm, C. J. (2006). Macroeconomic conditions, health, and mortality. In Jones, A. M. ed. The Elgar companion to health economics. Cheltenham, UK: Edward Elgar.

Ruhm, C. J. (2008). Macroeconomic conditions, health, and government policy. In Schoeni, R. F., House, J. S., Kaplan, G. \& Pollack, H. Making Americans healthier: Social and economic policy as health policy. New York: Russell Sage.

Schofield, R. (1985). The impact of scarcity and plenty on population change in England, 1541-1871 in Rotberg, R. I. et al. eds., Hunger and history: The impact of changing food production and consumption patterns on society. New York: Cambridge University Press.

Shryock, H.S., Siegel, J. S. et al. (1973). The methods and materials of demography. Washington, DC: US Bureau of the Census.

Søgaard, J. (1992). Econometric critique of the economic change model of mortality. Social Science \& Medicine, 34(9), 947-957.

Sokejima, S. \& Kagamimori, S. (1998). Working hours as a risk factor for acute myocardial infarction in Japan: a case-control study. BMJ, 317, 775-80.

Statistics Sweden (2005). www.scb.se. Data downloaded in 2005-2009.

Svensson, M. (2007). Do not go breaking your heart: Do economic upturns really increase heart attack mortality? Social Science \& Medicine, 65, 833-841.

Svensson, M. (2010). Economic upturns are good for your health but watch out for accidents: a study on Swedish regional data 1976-2005. Applied Economics 42(5):615 - 625. 
Tapia Granados, J.A. (2005a). Recessions and mortality in Spain, 1980-1997. European Journal of Population, 21(4), 393-422.

Tapia Granados, J.A. (2005b). Increasing mortality during the expansions of the US economy, 1900-1996. International Journal of Epidemiology, 34(6), 1194-1202.

Tapia Granados, J.A. (2005c). Economic growth, business fluctuations and health progress. International Journal of Epidemiology, 34(6). 1226-1233.

Tapia Granados, J.A. (2006). Mortality effects of the economic crisis in South Korea. International Journal of Epidemiology 35(5):1357.

Tapia Granados, J.A. (2008). Economic fluctuations and mortality in postwar Japan. Demography, 45(2), 323-343

Tapia Granados, J. A. \& E. L. Ionides. (2008). The reversal of the relation between economic growth and health progress: Sweden in the $19^{\text {th }}$ and $20^{\text {th }}$ centuries. Journal of Health Economics, 27:544-563.

Tapia Granados, J. A. \& Diez Roux, A.V. (2009). Life and death during the Great Depression. Proceedings of the National Academy of Sciences of the USA, 106(41):17290-17295.

Tapinos, G. P., Mason, A. \& Bravo, J. (1997). Demographic responses to economic adjustment in Latin America. New York: Clarendon Press.

Thomas, D. S. (1927). Social aspects of the business cycle. New York: Knopf.

Thomas, D. S. (1941). Social and economic aspects of Swedish population movements, 1750-1933, Macmillan: New York.

Valkonen, T, Martikainen, P. et al. (2000). Changes in socioeconomic inequalities in mortality during an economic boom and recession among middle-aged men and women in Finland. European Journal of Public Health 10(4):274-280.

Venables, W.N. \& Ripley, D. D. (2002). Modern applied statistics with $S, 4^{\text {th }}$ ed. New York: Springer.

Wagstaff, A. (1985). Time series analysis of the relationship between unemployment and mortality: A survey of econometric critiques and replications of Brenner's studies. Social Science \& Medicine 21(9), 985-996.

Winter, J. (1983). Unemployment, nutrition and infant mortality in Britain, 1920-50" in The Working Class in Modern British History: Essays in Honour of Henry Pelling, Cambridge University Press, Cambridge.

WHO-HFA (2005). Heath For All Database, European Regional Office, World Health Organization. http: \|www.euro.who.int/hfadb. Data downloaded between 2005 and 2010. Zolotas, X. (1981). Economic growth and declining social welfare. Athens/New York. Bank of Greece/New York University Press. 